San Jose State University

SJSU ScholarWorks

Master's Theses

Master's Theses and Graduate Research

Summer 2016

\title{
The Impact of Climate Change on Coastal Fog Hours of California's Central Coast
}

Chrissy Rogers

San Jose State University

Follow this and additional works at: https://scholarworks.sjsu.edu/etd_theses

\section{Recommended Citation}

Rogers, Chrissy, "The Impact of Climate Change on Coastal Fog Hours of California's Central Coast" (2016). Master's Theses. 4737.

DOI: https://doi.org/10.31979/etd.5r4q-6ydk

https://scholarworks.sjsu.edu/etd_theses/4737

This Thesis is brought to you for free and open access by the Master's Theses and Graduate Research at SJSU ScholarWorks. It has been accepted for inclusion in Master's Theses by an authorized administrator of SJSU ScholarWorks. For more information, please contact scholarworks@sjsu.edu. 


\title{
THE IMPACT OF CLIMATE CHANGE ON COASTAL FOG HOURS OF CALIFORNIA'S CENTRAL COAST
}

\author{
A Thesis \\ Presented to \\ The Faculty of the Department of Meteorology and Climate Science \\ San José State University
}

In Partial Fulfillment

of the Requirements for the Degree

Master of Science

\author{
by \\ Chrissy Rogers \\ August 2016
}


(C) 2016

Chrissy Rogers

ALL RIGHTS RESERVED 
The Designated Thesis Committee Approves the Thesis Titled

THE IMPACT OF CLIMATE CHANGE ON COASTAL FOG HOURS OF CALIFORNIA'S CENTRAL COAST

by

Chrissy Rogers

APPROVED FOR THE DEPARTMENT OF METEOROLOGY AND CLIMATE SCIENCE

SAN JOSÉ STATE UNIVERSITY

August 2016

Dr. Eugene Cordero Department of Meteorology and Climate Science

Dr. Martin Leach Department of Meteorology and Climate Science

Alicia Torregrosa Western Geographic Science Center, US Geological Survey 


\section{ABSTRACT \\ THE IMPACT OF CLIMATE CHANGE ON COASTAL FOG HOURS OF CALIFORNIA'S CENTRAL COAST}

by

\section{Chrissy Rogers}

This study used observations and downscaled model output from the Coupled Model Intercomparison Project 5 to investigate diurnal temperature differences and their relationship to the number of fog hours in the future along California's central coast. The study area extended north-south from Bodega Bay to the Santa Lucia Range and east-west from the coast of California to the western flank of the Sierra Nevada Mountains. Analyses of Representative Concentration Pathway (RCP) scenarios 4.5 and 8.5 showed that most of California's central coast will likely see minimal changes in the number of fog hours per day through the turn of the century. However, fog hours in the northern portion of the study area showed a reduction of up to an hour and a half per day, while southern areas showed an increase by more than an hour and a half per day by the turn of the century. The implications of these changes will vary depending on the timing of the increase or decrease. Further research is needed to look at timing of fog events. 


\section{ACKNOWLEDGEMENTS}

I would like to thank my family, friends, and the faculty at SJSU, UCSC, and UTA for their past, present and continued support and encouragement. I would also like to thank my Thesis Advisor Dr. Eugene Cordero for his support and advice along with the rest of my thesis committee, Dr. Martin Leach and Alicia Torregrosa, for their guidance and direction. Furthermore, I would like to thank the Girl Scouts of Northern California and more specifically John Swader (aka Awesome) for allowing me to place a weather station at Skylark Ranch. Additionally, I would like to acknowledge the following:

i. The World Climate Research Programmer's Working Group on Coupled Modelling, which is responsible for CMIP, and I thank the climate modeling groups (listed in Table 1 of this paper) for producing and making available their model output. For CMIP, the U.S. Department of Energy's Program for Climate Model Diagnosis and Intercomparision provides coordinating support and led the development of software infrastructure in partnership with the Global Organization for Earth System Science Portals.

ii. The "Downscaled CMIP3 and CMIP5 climate and Hydrology Projections" archived at http://gdo-dcp.ucllnl.org/downscaled_cmip_projections.

iii. This study was made possible in part due to the data made available by governmental agencies, commercial firms, and educational institutions participating in MesoWest. 
iv. Partial funding for this study was provided by the Pepperwood Foundation. 


\section{Table of Contents}

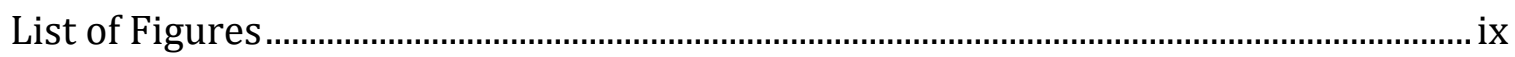

List of Tables.........................................................................................................................

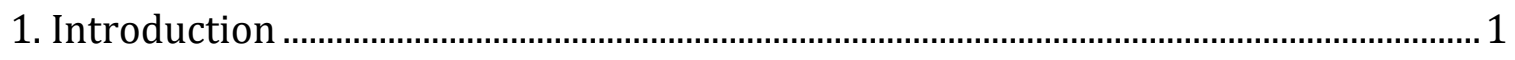

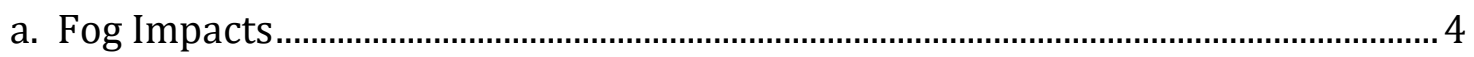

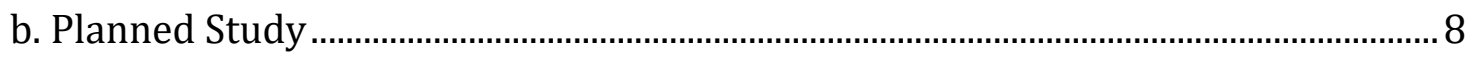

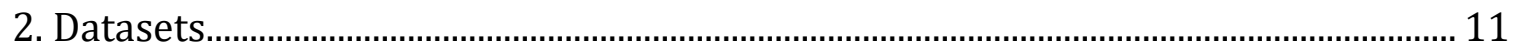

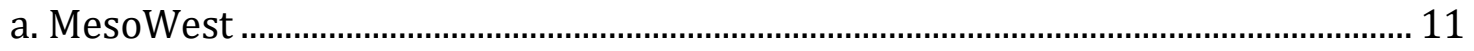

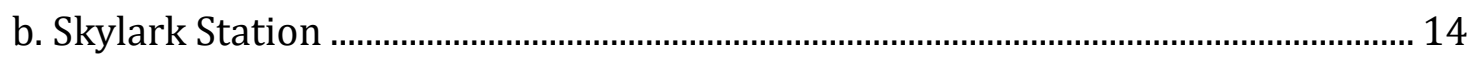

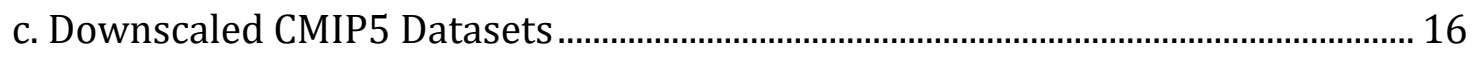

d. Satellite Derived Observational Fog........................................................................ 19

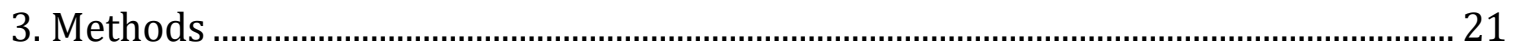

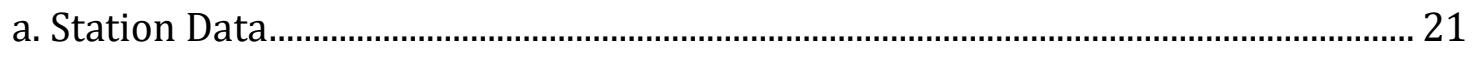

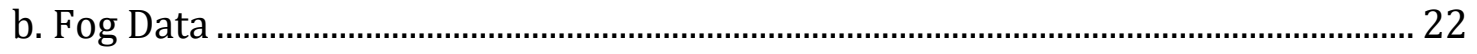

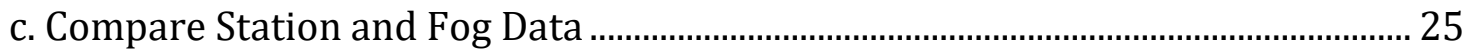

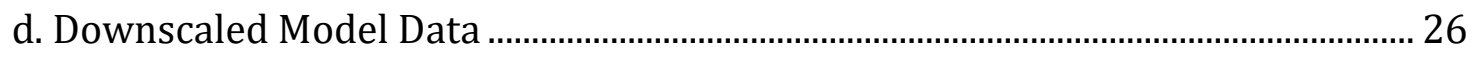

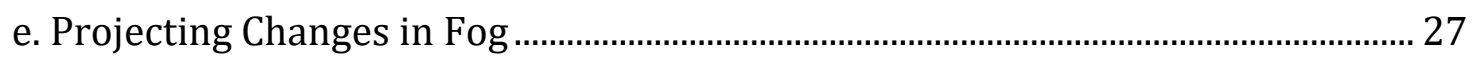

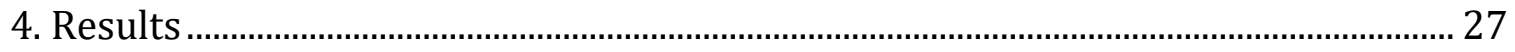

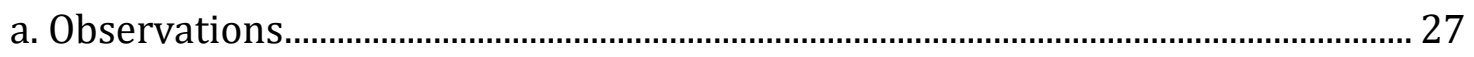


b. Downscaled Climate Models ....................................................................................... 38

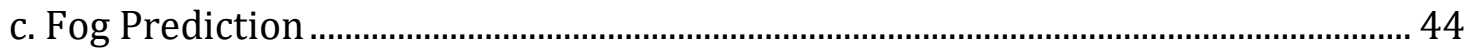

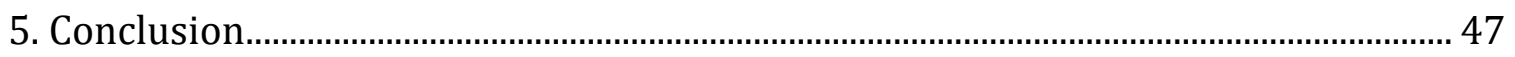

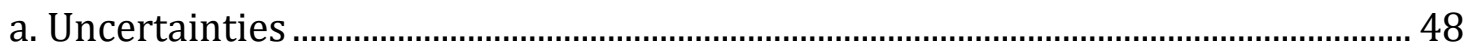

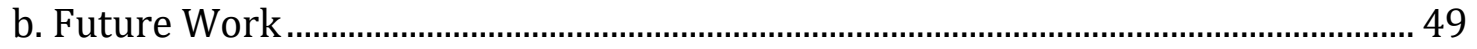

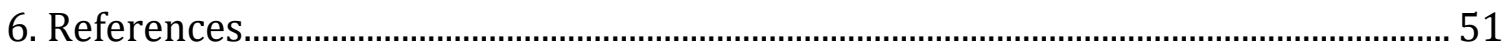

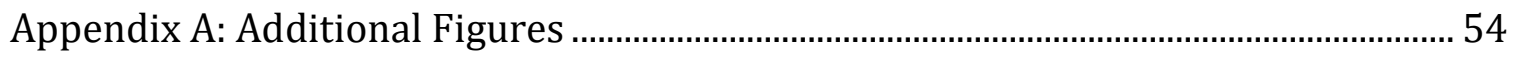




\section{List of Figures}

Fig. 1 Various images of coastal marine fog. …..................................................................... 1

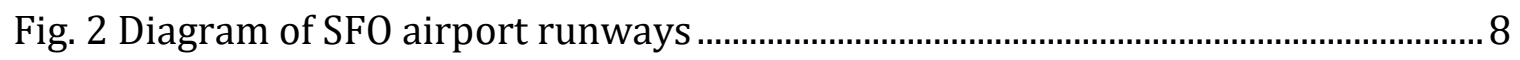

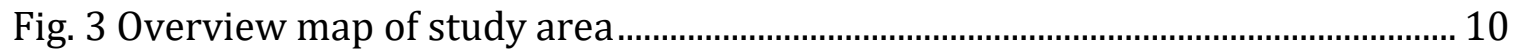

Fig. 4 Locations of MesoWest stations in the study area................................................. 12

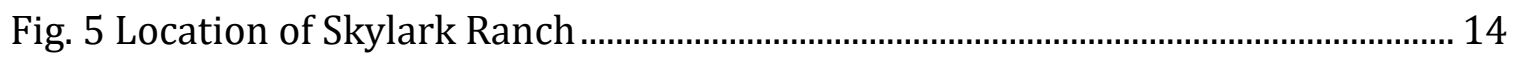

Fig. 6 Skylark Ranch Weather Station........................................................................ 15

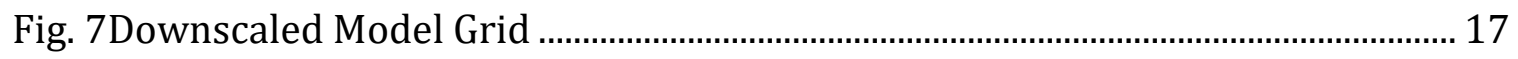

Fig. 8 Raw observed fog hours from GOES-West images. .............................................. 20

Fig. 9 Fog hours averaged to the same resolution a downscaled CMIP5 data sets.... 23

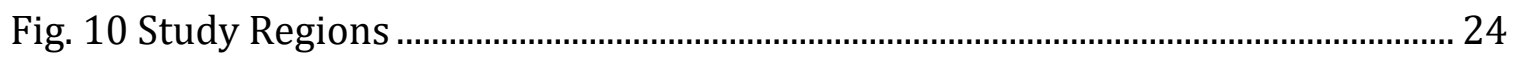

Fig. 11 Average fog hours and diurnal temperature difference. .................................... 33

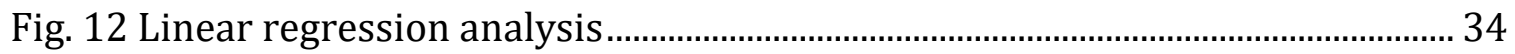

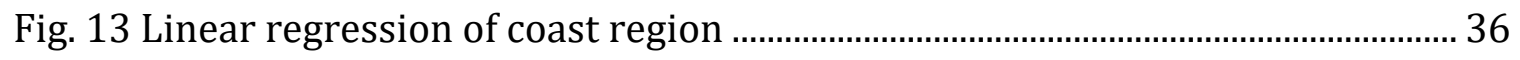

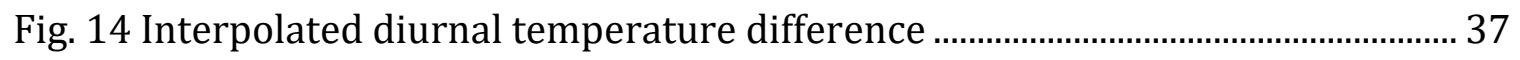

Fig. 15 Minimum daily temperatures from RCP 4.5 (ensemble averages)................... 40

Fig. 16 Multi-model decadal means for coast region. ...................................................... 41

Fig. 17 Variance between model values and observed values ....................................... 43

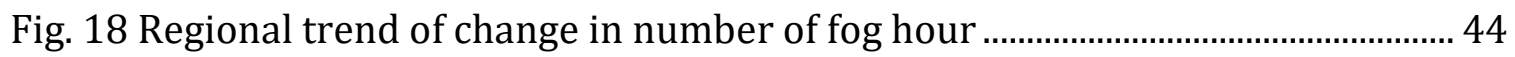

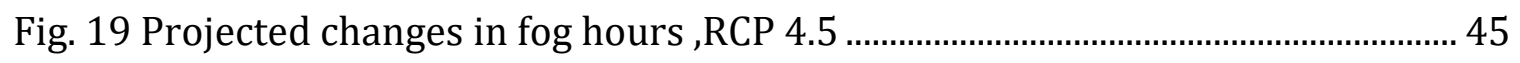

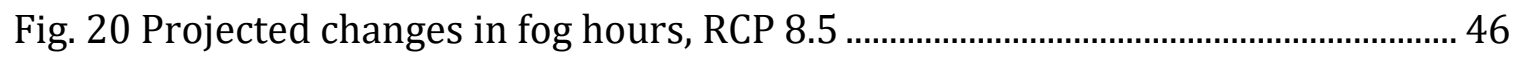

Fig. A1 Minimum daily temperatures from RCP 8.5 (ensemble averages) ................... 54

Fig. A2 Maximum daily temperatures from RCP 4.5 (ensemble averages).................. 55 
Fig. A3 Maximum daily temperatures from RCP 8.5 (ensemble averages).................. 55

Fig. A4 Diurnal temperature difference from RCP 4.5 (ensemble averages) ............... 55

Fig. A5 Diurnal temperature difference from RCP 8.5 (ensemble averages) ............... 55 


\section{List of Tables}

Table 1 List of MesoWest Stations used in Study and their associated network........ 13

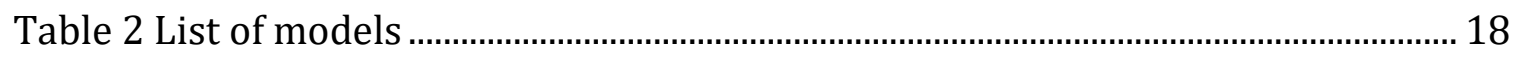

Table 3 Valley region station correlation values .............................................................. 29

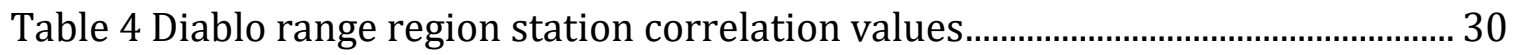

Table 5 Coast region station correlation values ................................................................ 31 


\section{Introduction}

California has a Mediterranean climate with warm, wet winters and hot, dry summers with little to no precipitation during the summer months (June - Sept) (Palmer 1917; Torregrosa et al. 2016). However, during the typically hot summer months, much of the coast of California is relatively cool. The low temperatures are the result of low clouds (Fig. 1), which are nearly constant throughout the summer months (Schwartz et al. 2014). These low clouds are commonly referred to as fog.
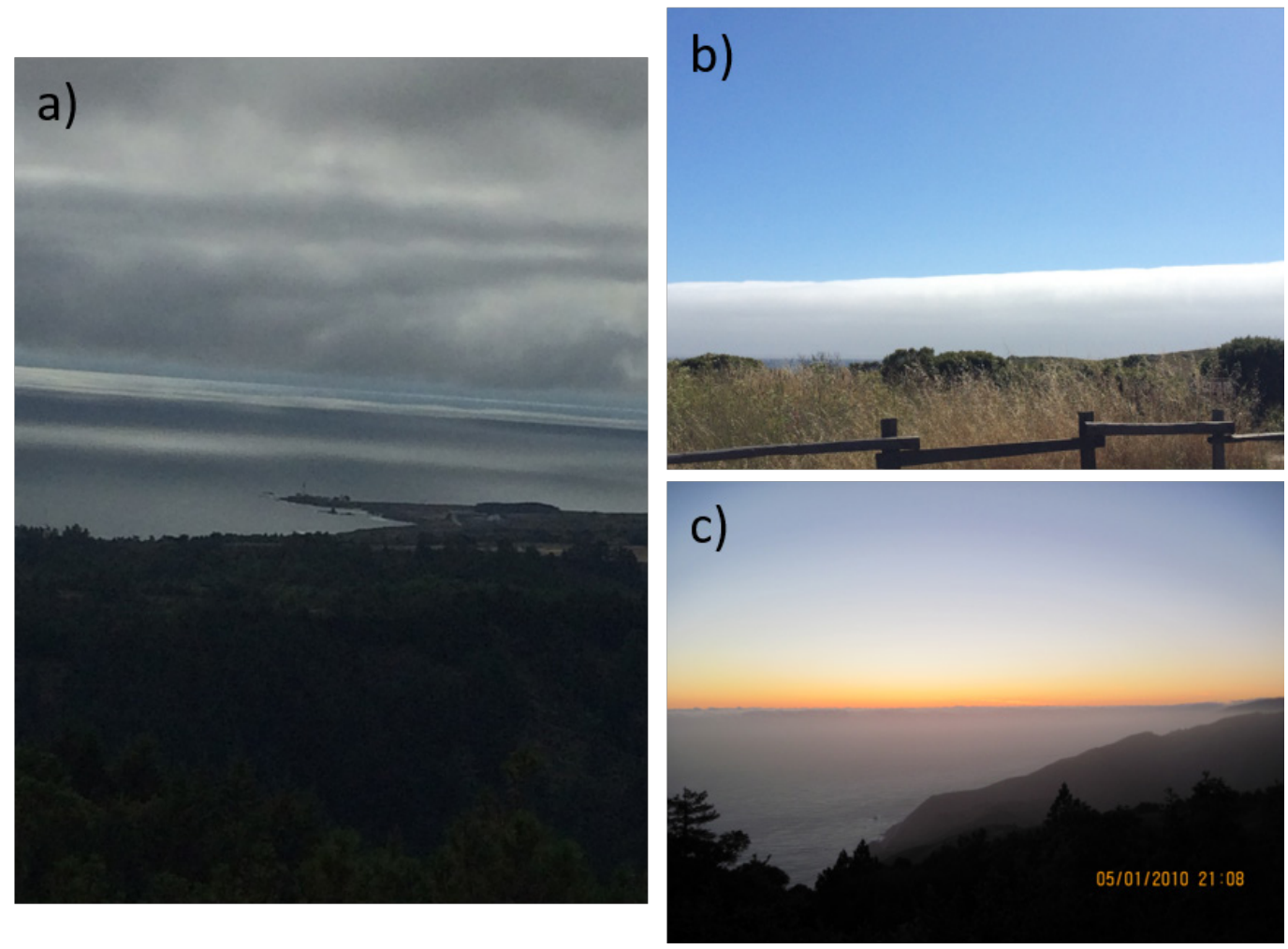

Fig 1: Various images of coastal marine fog: a) taken from Inspirations Point at Skylark Ranch overlooking Pigeon Point Lighthouse, b) taken on the northern end of Año Nuevo State Park, c) taken at University of California's Landel-Hills Big Creek Reserve in Big Sur, CA. 
The American Meteorological Society defines fog as a cloud (water droplets suspended in the atmosphere) with its base at the Earth's surface, which reduces visibility below $1 \mathrm{~km}$ (0.62 miles) (American Meteorological Society 2012). The two primary types of fog, which occur over land, are advection fog and radiation fog (Koračin et al. 2001). The summertime coastal fog is advection fog, which forms as warm moist air blows over cold coastal waters by westerly winds (Ahrens 2011; Burgess and Dawson 2004). The fog bank (stratocumulus clouds) on the eastern margin of the Pacific Ocean extends approximately 50 miles to the west and is usually 1500 feet in thickness (Palmer 1917). The stratocumulus clouds form on eastern boundary currents, like the California Current, and have a seasonal and diurnal cycle in some areas (Wood 2012).

During the summer months, coastal fog develops because the winds are typically northerly to northwesterly. As a result, a pressure gradient develops between the North Pacific High and the Continental Thermal Low (García-Reyes and Largier 2012; Dorman et al. 2013; Johnstone and Dawson 2010; Palmer 1917; Clark and Wilson 1996; Ahrens 2011). The northerly winds flow parallel to the coast due in part to the coastal mountains (Dorman et al. 2013). The wind stress on the ocean surface causes surface water to move to the right of the direction of the wind in a process known as Ekman Transport. As the surface water moves westward, cold nutrient-rich water from depth moves up to replace it; this process is known as upwelling (Ahrens 2011; Johnstone and Dawson 2010; Palmer 1917; García-Reyes and Largier 2012). The upwelling reduces the sea surface temperature (SST) by as 
much as $10^{\circ} \mathrm{F}$ near Cape Mendocino, CA (Ahrens 2011). A surface-based inversion forms as warmer air moves across the upwelled waters. Radiative cooling and heating from the sea surface start the mixing and lifting of the marine layer (Hiatt et al. 2012). Subsidence from the North Pacific High strengthens the inversion, lowering the clouds and inhibiting precipitation, resulting in dry summers (Hiatt et al. 2012; Dorman et al. 2013; Ahrens 2011; Torregrosa et al. 2016; Johnstone and Dawson 2010; O’Brien et al. 2013; Koračin et al. 2014).

The inland intrusion of coastal fog is a result of temperature gradients between the Central Valley/Diablo Range and the coast. Heating from the central valley causes air to rise. As warm air rises, air from the west is drawn in (the Sierra Mountains block air from the east) through breaks in the Coast Range (Palmer 1917). This influx of air draws the fog on-shore. Fog near the ground dissipates quickly from surface heating leaving the layer of low clouds (Ahrens 2011) or high fog (Palmer 1917).

The inversion base height ultimately determines how far the fog intrudes inland. Typically, the inversion base is $400-500 \mathrm{~m}(\sim 1300-1600 \mathrm{ft})$, which is lower than much of the Coast Range and Santa Cruz Mountains. The height of the inversion limits the inland intrusion of fog to the coast except through gaps such as the San Bruno Gap and the Crystal Springs Gap. As the inversion height increases, the Coastal Mountains cannot block the fog intrusion (Clark and Wilson 1996; Johnstone and Dawson 2010; Torregrosa et al. 2016; Koračin et al. 2014). 
The number of fog hours varies spatially and temporally. Leipper (1994) found lighthouse and lightship stations had five times more fog hours than National Ocean and Atmospheric Administration (NOAA) and National Weather Service (NWS) stations, which are further inland. Over a 46-year record, the San Francisco lightship showed an average of 1066 hours of dense fog per year with a maximum of 1674 hours (not including low cloud/high fog). Hartmann et al. (1992) showed summertime low clouds have a net radiative forcing of -15 to $-25 \mathrm{~W} \mathrm{~m}^{-2}$ predominantly from reducing incoming solar radiation. As a result of this decrease in radiative forcing, changes in the number of fog hours could have significant impacts on coastal ecosystems, energy use and infrastructure, forest fire patterns, fishing, transportation, and human life.

\section{a. Fog Impacts}

Fog not only impacts the environment but society as well. The cooler temperatures in foggy areas tend to reduce energy consumption, used for irrigation pumping and air conditioning (Koračin et al. 2014). Fog affects solar electricity production on the coast (Schwartz et al. 2014). Coastal communities are acclimated to the cool summers and are less able to adapt to extreme heat events due to lack of central air conditioning or window units (Gershunov et al. 2011). Regarding air conditioning, California ranks $38^{\text {th }}$ in the nation with only $54 \%$ of homes having some form of air conditioning. Coastal areas such as the San Francisco Bay Area have even fewer homes with air conditioning ( $21 \%$ of homes). Gershunov et al. (2011) found a strong correlation between both temperature and relative humidity 
values with emergency room visits in the San Francisco and Monterey Bay areas. Extreme heat events on the coast could increase the death rates of not only humans but also intertidal species and plant life (Torregrosa et al. 2016) such as the coastal redwood trees (Sequoia sempervirens).

Redwood trees (Sequoia sempervirens) are the tallest living tree species and some of the oldest with trees $\sim 2000$ years old (Johnstone and Dawson 2010). These trees are found between $\sim 42^{\circ} \mathrm{N}$ and $36^{\circ} \mathrm{N}$ along the western coast of the United States and never exceed more than 30 miles inland (Johnstone and Dawson 2010; Palmer 1917). The limits of the coastal redwoods are defined by areas with frequent fog events such as Big Sur, CA, which is home to a large number of rare, endangered and threatened plant and animal species (Hiatt et al. 2012; Burgess and Dawson 2004). Johnstone and Dawson (2010) found Quaternary pollen evidence, which showed a reduction in redwood populations during glacial periods. During glacial periods upwelling is likely reduced and therefore, reduces fog events. Their study and studies by Dawson (1998) indicate a reliance on cool and humid marine conditions for redwood and other endemic species growth and survival. Native perennial grasses are also able to live through the summer droughts and are only found in coastal areas with frequent fog (Corbin et al. 2005). The reliance of redwoods and native grasses on cool damp conditions suggests that changes to the duration of fog would affect the distribution of these plants along the Pacific Northwest coast. 
Fog is an important water source in coastal ecologic systems. Fog droplets are tiny (only 1-40 $\mu \mathrm{m}$ ), so they do not readily precipitate out without interactions with solid objects. Pine needles, fern fronds, spider webs, and native grasses make excellent fog collectors as air flows through them (Burgess and Dawson 2004; Torregrosa et al. 2016; Corbin et al. 2005). Dawson (1998) found 34\% of total annual water inputs in coastal redwood forests came from fog drip. During the summer months' redwoods obtained an average of $18.6 \%$ of their water from fog drip, and the plants under the canopy obtained an average $\sim 66.5 \%$ of the water from the fog drip. During extremely dry years such as 1994, some species of plants obtained $100 \%$ of their water from fog drip from the canopy above.

During fog events, the increased relative humidity and lower temperatures help alleviate stress on coastal plants by reducing the atmospheric vapor pressure deficit. This reduction slows evapotranspiration rates from the forest plants (Torregrosa et al. 2016; Burgess and Dawson 2004). Photosynthesis and carbon uptake are also noticeably higher on foggy days than on sunny days. Increase in microbial activities during foggy days increase available nutrients in the soil (Koračin et al. 2014). In addition, redwoods, native coastal grasses, and up to $80 \%$ of other plant species can obtain water from the fog directly through their leaves before the fog drips to forest floor (Burgess and Dawson 2004; O'Brien et al. 2013).

The typically dry conditions during summer in California means fire season. The coastal fog changes fire hazards over very short distances; moving inland from the coast, the fog dissipates and the potential for fire increases (Norman et al. 2009). 
A decrease in fog frequency may also increase the likelihood of forest fires in coastal forests (Torregrosa et al. 2016).

Fog also has a strong impact on transportation due to reduced visibility. Many shipwrecks (32\% worldwide) have occurred along the coast due to fog (Palmer 1917; Koračin et al. 2014). Before the days of navigation systems, the fog prevented navigators from using astronomical methods to locate themselves at sea. Additionally, even if the navigator knows where they are, there may still be collisions with other vessels because the fog obscures their visibility (Palmer 1917), this is still a problem today. This inability to see other ships is also a significant problem at airports like San Francisco International Airport (SFO). SFO is one of the busiest airports in the U.S. The fog at SFO causes delayed flights, missed connections, and disturbances to airports across the country (Clark and Wilson 1996). SFO has the most hours of delayed flights across the U.S., which is primarily caused by fog. The fog is an issue because of runway layout, wind direction, and mountains.

Coastal fog has been shown to slow arrivals at SFO because of airport infrastructure and FAA safety regulations (Clark and Wilson 1996). SFO has two sets of runways, which run parallel to each other and are $\sim 750$ feet apart (Fig. 2) (Clark and Wilson 1996; Federal Aviation Administration 2016). 


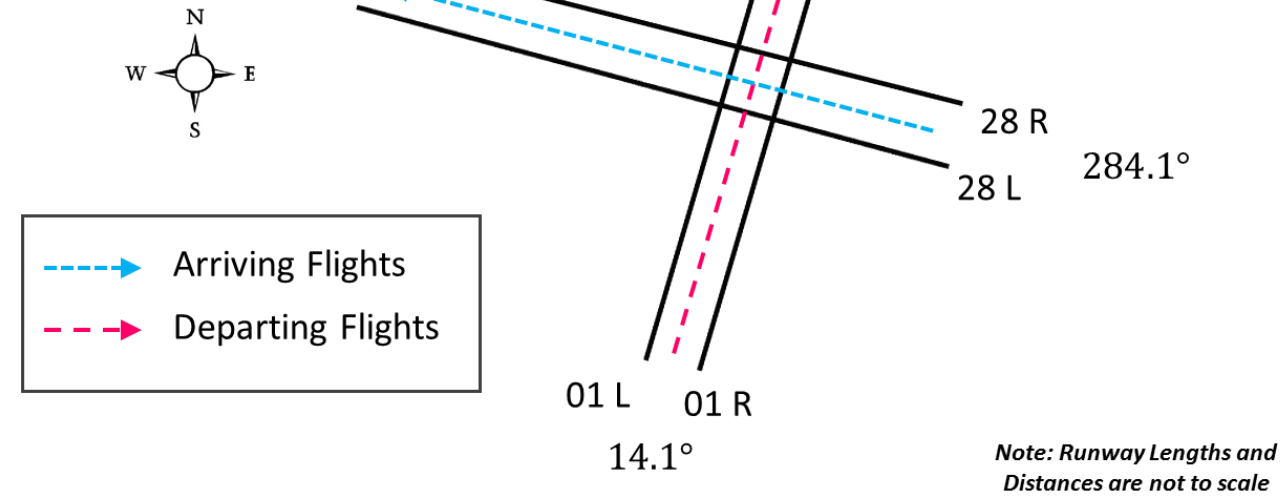

Fig 2 Diagram of SFO airport runways. Diagram shows the general summertime flight pattern at SFO.

The dominant wind direction in the summer is from the north, which sets up the flight pattern at SFO. SFO has arrivals landing on runways $28 \mathrm{~L}$ and $28 \mathrm{R}$ and departing flights on runways $01 \mathrm{~L}$ and $01 \mathrm{R}$ (Fig. 2) under normal Visible Flight Rules (VFR) flights are allowed to merge in pairs to land on both runways simultaneously allowing 50-55 planes to land per hour. This merger occurs 5-15 miles away from the airport and due to mountains, this merger occurs at $\sim 3500$ feet. When fog is present planes cannot see each other during this merger. Therefore, they cannot land simultaneously and must be staggered, reducing landing rates to 30-35 planes per hour (Clark and Wilson 1996).

\section{b. Planned Study}

The purpose of this study was to investigate the diurnal temperature difference and their relationship to the number of fog hours. This relationship was used along with downscaled model output from the Coupled Model Intercomparison 
Project 5 (CMIP5) to evaluate how climate change may affect the number of fog hours in the future along California's central coast. Fig. 3 shows the study area, which extends north to south from Bodega Bay to the Santa Lucia Range and extends east to the western flank of the Sierra Nevada Mountains. 


\section{Research Area (Overview Map)}

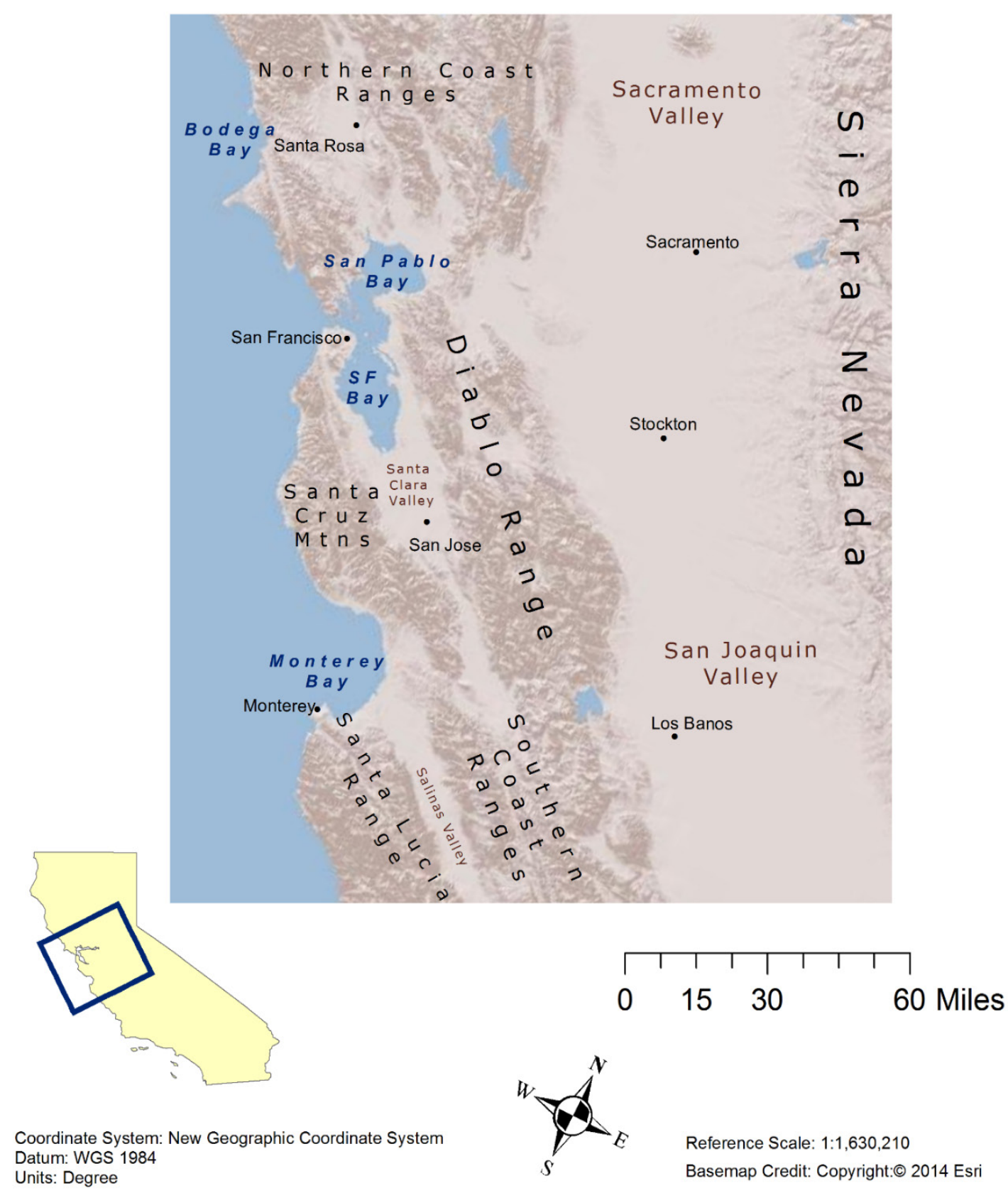

Fig. 3 Overview map of study area 


\section{Datasets}

All observational data, except data from the Skylark station, were obtained from the University of Utah's MesoWest website (Horel et al. 2002). The Skylark station was set up to collect data from 6 June 2014 to 20 August 2014 at Skylark Ranch's Inspiration Point. The CMIP5 climate model data sets were obtained from Downscaled CMIP3 and CMIP5 Climate and Hydrology Projections archive (Maurer et al. 2007). Observational fog-hours were obtained from Alicia Torregrosa at the US Geological Survey, Western Geographic Science Center (Torregrosa et al. 2016). a. MesoWest

MesoWest collects and stores weather measurements from automated and manual weather stations across the western U.S. Some examples of archived measurements are: temperature, pressure, precipitation, wind speed and direction, and relative humidity. The datum is provided to MesoWest voluntarily from governmental and commercial organizations. The MesoWest database contains measurements from 1997 through the present (Horel et al. 2002). The data obtained from MesoWest included temperature observations from the National Weather Service (NWS) and RAWS networks (see Table 1 and Fig. 4) within the study region (see Fig. 3). The RAWS network is "coordinated by the Bureau of Land Management and U.S. Forest Service" (Horel et al. 2002). 


\section{Stations in Research Area}

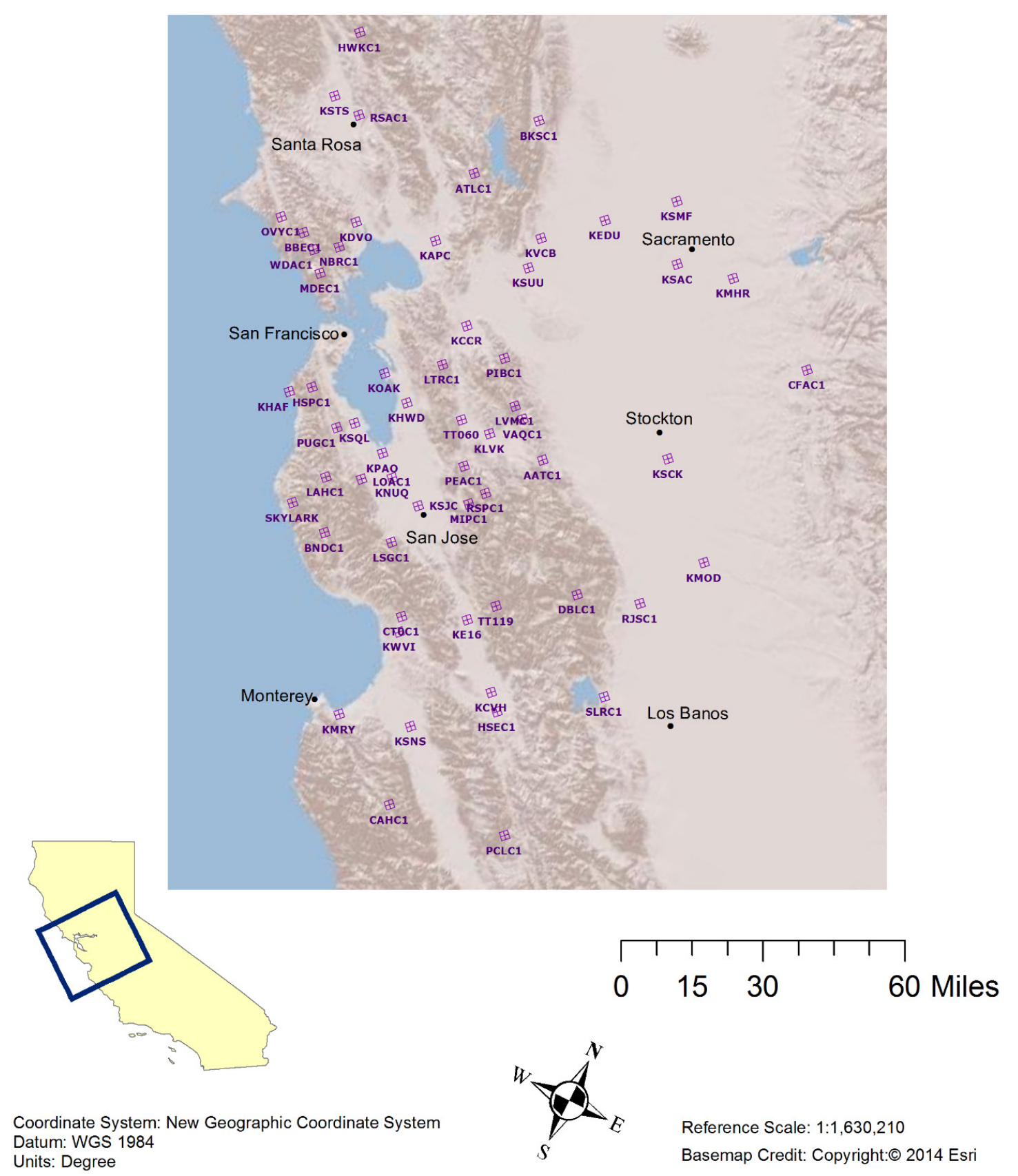

Fig. 4 Locations of MesoWest stations in the study area. Also includes Skylark Station 
Table 1 List of MesoWest stations used in study and their associated network.

\begin{tabular}{|c|c|c|c|c|c|}
\hline Station & Network & Station & Network & Station & Network \\
\hline AATC1 & RAWS & KMAE & NWS & LVMC1 & RAWS \\
\hline ASRC1 & RAWS & KMCE & NWS & MDEC1 & RAWS \\
\hline ATLC1 & RAWS & KMER & NWS & MIPC1 & RAWS \\
\hline BBEC1 & RAWS & KMHR & NWS & MRQC1 & RAWS \\
\hline BKSC1 & RAWS & KMOD & NWS & NBRC1 & RAWS \\
\hline BNDC1 & RAWS & KMRY & NWS & OKSC1 & RAWS \\
\hline CAHC1 & RAWS & KMYV & NWS & ONOC1 & RAWS \\
\hline CFAC1 & RAWS & KNUQ & NWS & OVYC1 & RAWS \\
\hline CMAC1 & RAWS & KNXC1 & RAWS & PCEC1 & RAWS \\
\hline CTOC1 & RAWS & K069 & NWS & PCLC1 & RAWS \\
\hline DBLC1 & RAWS & KOAK & NWS & PEAC1 & RAWS \\
\hline FHLC1 & RAWS & KPAO & NWS & PIBC1 & RAWS \\
\hline HDZC1 & RAWS & KSAC & NWS & PLEC1 & RAWS \\
\hline HSEC1 & RAWS & KSCK & NWS & PPSC1 & RAWS \\
\hline HSPC1 & RAWS & KSJC & NWS & PUGC1 & RAWS \\
\hline HWKC1 & RAWS & KSMF & NWS & RJSC1 & RAWS \\
\hline KAPC & NWS & KSNS & NWS & RSAC1 & RAWS \\
\hline $\mathrm{KBAB}$ & NWS & KSQL & NWS & RSPC1 & RAWS \\
\hline KCCR & NWS & KSTS & NWS & SLRC1 & RAWS \\
\hline $\mathrm{KCVH}$ & NWS & KSUU & NWS & SLWC1 & RAWS \\
\hline KDVO & NWS & KUKI & NWS & SRTC1 & RAWS \\
\hline KE16 & NWS & KVCB & NWS & TS623 & RAWS \\
\hline KEDU & NWS & KWVI & NWS & TT060 & RAWS \\
\hline KELC1 & RAWS & LAHC1 & RAWS & TT119 & RAWS \\
\hline KFAT & NWS & LICC1 & RAWS & VAQC1 & RAWS \\
\hline KHAF & NWS & LOAC1 & RAWS & WDAC1 & RAWS \\
\hline KHWD & NWS & LSGC1 & RAWS & & \\
\hline KLHM & NWS & LTRC1 & RAWS & & \\
\hline
\end{tabular}

The temporal frequency of the station measurements ranges from 5 to 60 minutes depending on station and weather conditions. To account for these variations, hourly averages were calculated for each station. 


\section{b. Skylark Station}

The initial purpose of this station was to have a control station to verify fog. This station contained a camera to capture images in multiple bands, including visible and infrared (IR), every hour. The goal was to have visual confirmation of fog to coincide with temperature and relative humidity measurements at a coastal location. However, at the end of the sampling period, pictures from the camera were unable to be retrieved from the memory card. This glitch changed the course the research; nevertheless, the other datum collected was valuable because it filled in a coastal area with sparse measurements (Fig. 4).

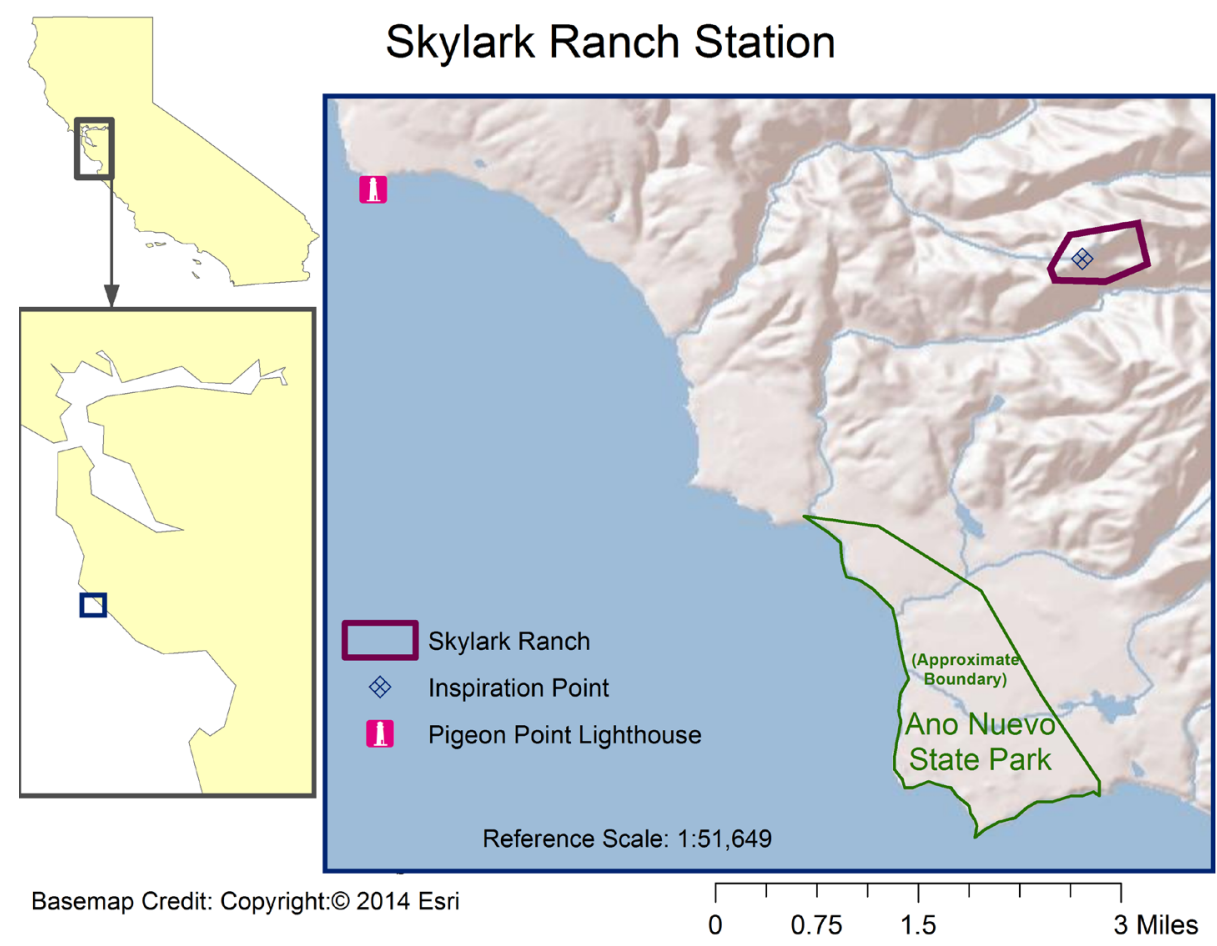

Fig. 5 Location of Skylark Ranch in relation to Año Nuevo State Park and Pigeon Point Lighthouse

Fig. 5 illustrates the location of Skylark Ranch and Inspiration Point. Skylark Ranch is roughly three miles north of Año Nuevo state park and Inspiration Point, 
the stations location, resides on a ridge $\sim 360.5 \mathrm{~m}(\sim 1180 \mathrm{ft}$.) above sea level. Fig. 6 is a photograph of the weather station at Inspiration Point looking toward the northwest. The Fire Weather Research Laboratory at San José State University provided the instrumentation used at this station.

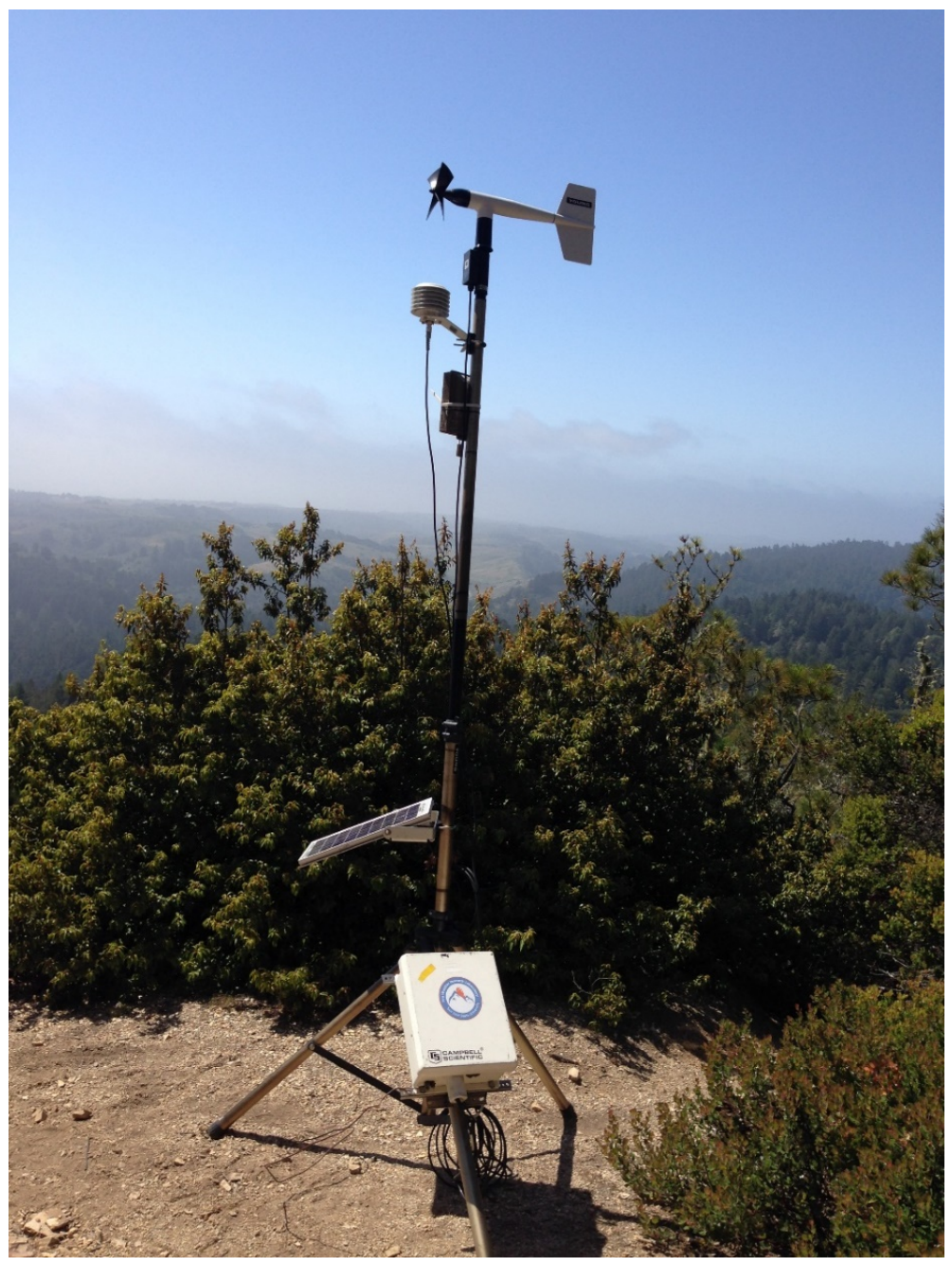

Fig. 6 Skylark Ranch Weather Station. Looking northwest from Inspiration Point at Skylark Ranch. Photographer: Chrissy Rogers

The weather station included the following: Campbell Scientific CR1000 data logger, Campbell Scientific CS215 temperature and relative humidity sensor, and RM Young 5103 anemometer and wind vane. The measurement frequency was 15 
minutes for all instruments between 6 June 2014 and 20 August 2014. The temperature data was later averaged to hourly to be analyzed with the MesoWest Data.

\section{c. Downscaled CMIP5 Datasets}

The CMIP5 project involved two types of experiments, long-term experiments (100 years) and near-term experiments (10-30 years) (Taylor et al. 2011). This project uses results from the long-term experiments, which started from the preindustrial control runs and ran through the end of the $21^{\text {st }}$ century (Taylor et al. 2011). The long-term experiments have three tiers of simulations, the core tier plus two optional tiers. Within the core tier are the representative concentration pathways (RCPs) 4.5 and 8.5 scenarios. The RCP scenarios are designed for mitigation purposes depicting various actions policy makers may take to reduce $\mathrm{CO}_{2}$ emissions (Taylor et al. 2011). The RCP labels 4.5 and 8.5 represent the approximate amount of additional radiative forcing, compared to preindustrial control runs, by the end of the century. RCP4.5 represents an additional $4.5 \mathrm{~W} \cdot \mathrm{m}^{-2}$ and RCP8.5 represents an additional $8.5 \mathrm{~W} \cdot \mathrm{m}^{-2}$ by the year 2100 from $\mathrm{CO}_{2}$ emissions. For more information on the CMIP5 experiments please refer to "An Overview of CMIP5 and the Experiment Design" by Taylor et al. (2011).

The CMIP5 models used in this study were downscaled to 1/8 degree using Bias-Correction Constructed Analogues version 2 (BCCAv2). Fig. 7 shows the locations of the $1 / 8$ degree grid used by the downscaled algorithm. 

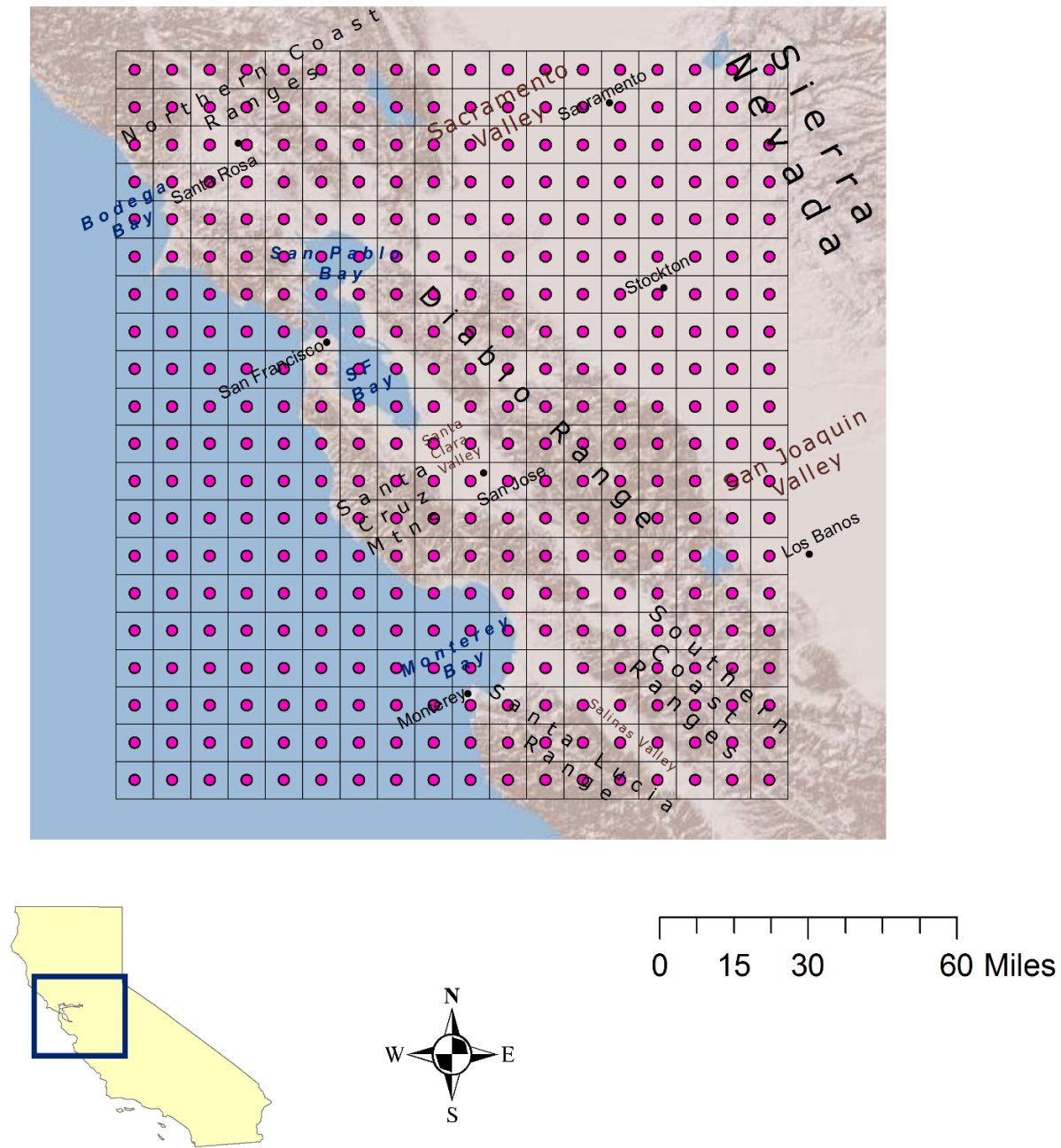

Coordinate System: New Geographic Coordinate System Datum: WGS 1984

Reference Scale: 1:0 Units: Degree

Basemap Credit: Copyright:@ 2014 Esri

Fig. 7 Downscaled Model Grid. Dots represent grid point locations in the CMIP5 downscaled model runs.

This dataset was retrieved at http://gdo-dcp.ucllnl.org/ (Maurer et al. 2007).

This method begins by taking into account how the Global Climate Model (GCM) compares to observations using a quantile mapping technique, which is applied relative to a Julian date. After this process, the model is adjusted to the specified resolution of $1 / 8$ degree using constructed analogs (Reclamation 2013). The 
variables used in this study are daily maximum surface air temperature (Tmax) and the daily minimum surface air temperature (Tmin).

Table 2 List of models and Modeling Centers associated with them, whose CMIP5 experiment data was downscaled and used in this study

\begin{tabular}{|l|c|}
\hline \multicolumn{1}{|c|}{ Modeling Center } & Model Name \\
\hline Beijing Climate Center, China Meteorological Administration & BCC-CSM1.1 \\
\hline Canadian Centre for Climate Modelling and Analysis & CanESM2 \\
\hline National Center for Atmospheric Research & CCSM4 \\
\hline $\begin{array}{l}\text { Commonwealth Scientific and Industrial Research Organization } \\
\text { in collaboration with Queensland Climate Change Centre of } \\
\text { Excellence }\end{array}$ & CSIRO-Mk3.6.0 \\
\hline NOAA Geophysical Fluid Dynamics Laboratory & $\begin{array}{c}\text { GFDL-CM3 } \\
\text { GFDL-ESM2G } \\
\text { GFDL-ESM2M }\end{array}$ \\
\hline Institute Pierre-Simon Laplace & $\begin{array}{c}\text { IPSL-CM5A-LR } \\
\text { IPSL-CM5A-MR }\end{array}$ \\
\hline $\begin{array}{l}\text { Japan Agency for Marine-Earth Science and Technology, } \\
\text { Atmosphere and Ocean Research Institute (The University of } \\
\text { Tokyo), and National Institute for Environmental Studies }\end{array}$ & $\begin{array}{c}\text { MIROC-ESM } \\
\text { MIROC-ESM- } \\
\text { CHEM } \\
\text { Meteorological Research Institute }\end{array}$ \\
\hline Norwegian Climate Centre & MRI-CGCM3 \\
\hline
\end{tabular}

Chosen models ran both the RCP 4.5 and RCP 8.5 scenarios and also the same number of ensembles in both scenarios. RCP 2.6 and RCP 6.0 are not used in this study, due to lack of models for these scenarios. Table 2 lists the models used in this study and the modeling center that created them. The model temperatures are analyzed between 1950 and 2090. This dataset does not provide projections over the ocean because the downscaling technique requires historical data. 


\section{d. Satellite Derived Observational Fog}

An observational fog and low cloud cover (FLCC) dataset was derived from The National Oceanic and Atmospheric Administration (NOAA) Geostationary Operational Environmental Satellite (GOES) West imagery. The raster dataset shown in Fig. 8 is available for download at http://climate.calcommons.org/datasets/summertime-fog. The raster resolution is $4 \mathrm{~km}$ per pixel, and it contains the average summertime (June - September) fog hours per day. This raster was derived using eleven years (1999-2009) of hourly GOES-West images. The images were processed using methods detailed in (Combs et al. 2010, 2004) to create cloud cover maps "by the Cooperative Institute for Research in the Atmosphere (CIRA) as part of their Low-Cloud/Fog GOES-R Proving Ground Product" (California Landscape Conservation Cooperative). 


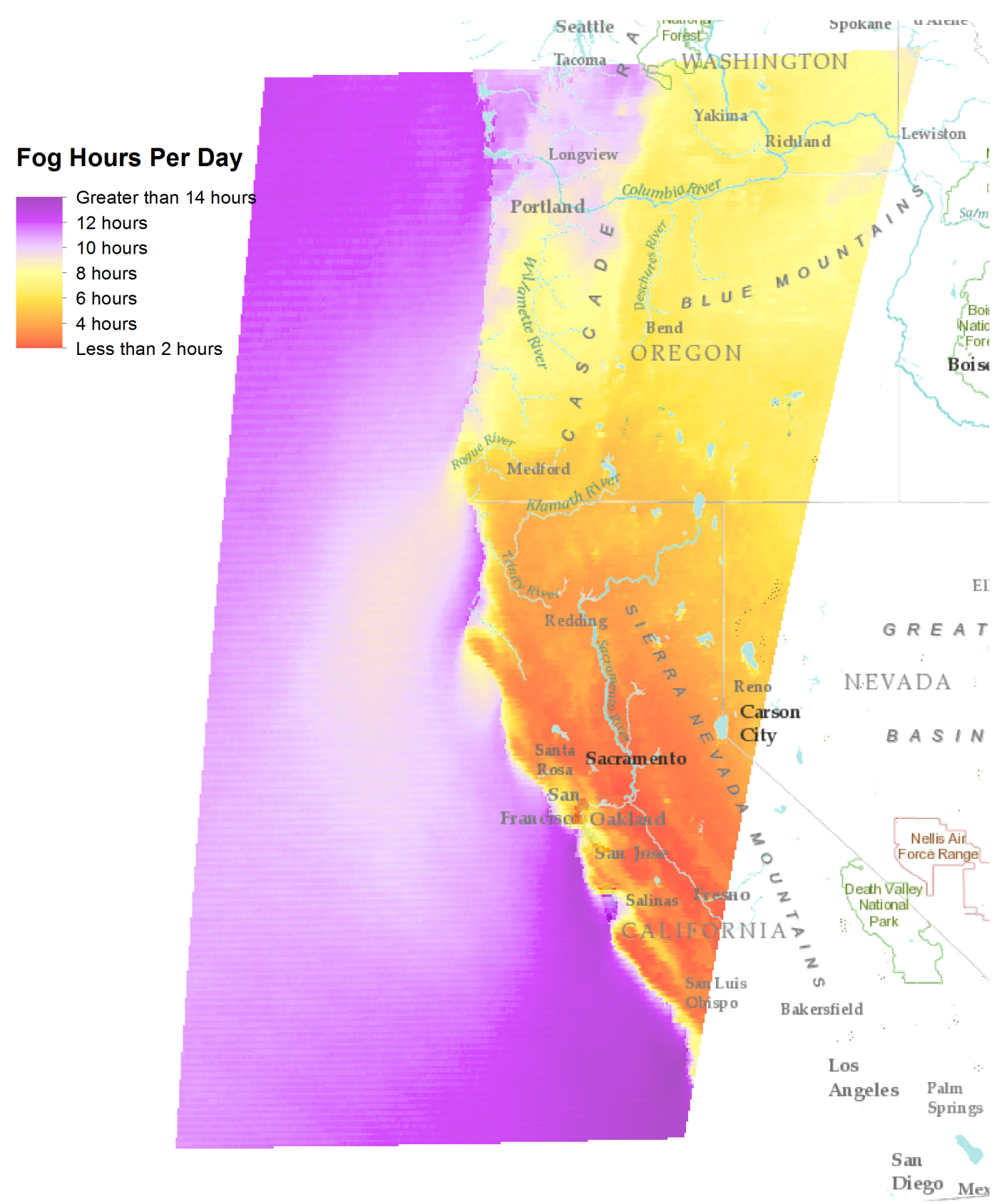

Base Map Credits: Sources: Esri, DeLorme, USGS, NPS

Fig. 8 Raw observed fog hours from GOES-West images. Average of summertime (June-Sept) fog/low cloud data from 1999-2009 obtained from http://climate.calcommons.org/datasets/summertime-fog 
This process utilizes channels 1 (visible light: $0.55-0.75 \mu \mathrm{m}$ ), 2 (shortwave infrared: $3.6 \mu \mathrm{m}$ ), and 4 (the longwave infrared: $10.7 \mu \mathrm{m}$ ) from the Imager sensor on GOES-West (Combs et al. 2010). Torregrosa et al. (2016) further processed this data with spatial statistics routines and identified specific images to be removed from calculations. Most of the removed images occurred at dawn and dusk; to compensate for this missing time frame images from the hour before and the hour after the deleted image were averaged together. The summer seasons were then averaged to obtain a decadal average of fog hours per 24-hour period. Fog hours range from greater than 14 hours over the ocean to less than 2 hours as you move inland (see Fig. 8).

\section{Methods}

A number of methods are utilized to help better understand how changes in the duration and location of fog are changing over the coming decades. Methods used in this study included post-processing the station, fog, and downscaled model data, finding relationships between station data and fog data, and projecting changes in fog into the future.

\section{a. Station Data}

A weather station was set up at Skylark Ranch on 6 June 2014. This station recorded data every $15 \mathrm{~min}$ through 2014 August 20. After data collection ended at this station, MesoWest was used to identify NWS and RAWS stations in the study area. The data for the period corresponding to the Skylark Station was downloaded for each identified MesoWest station. 
Hourly averages were calculated in order to analyze all station data at the same time frequency using Pandas 0.17.1-5 library for Python 2.7.6 (hereafter Pandas) (McKinney 2010, 2012). A correlation analysis was performed on all station data using Pandas. From this analysis, the stations were divided into three geographic regions: the coastal region, the diablo range region, and the central valley region.

At each station, the maximum (Tmax) and minimum (Tmin) temperatures were found for each day. The diurnal temperature difference (Tdiff) was calculated from these two values $\left\{T_{\text {diff }}=T_{\max }-T_{\min }\right\}$ at each station. Tdiff was averaged over the summer for each station. The average Tdiff was exported to ArcGIS 10.2.2 (ESRI 2014) (hereafter GIS) for further analysis to be discussed later.

\section{b. Fog Data}

The satellite-derived observational fog data, from Fig. 8, was averaged to the same resolution as the downscaled model data (Fig. 7) using the zonal statistics tool from the Spatial Analyst toolbox in GIS (ESRI 2014). Fig. 9 shows the results of this averaging. Similar to Fig. 8 the fog hours over the ocean are greater than 12-14 hours and progressively decrease inland to less than two hours in the central valley. The coastal regions have values of eight to twelve hours and inland intrusions can be seen into the San Francisco Bay Area and into the Salinas Valley from Monterey Bay. 


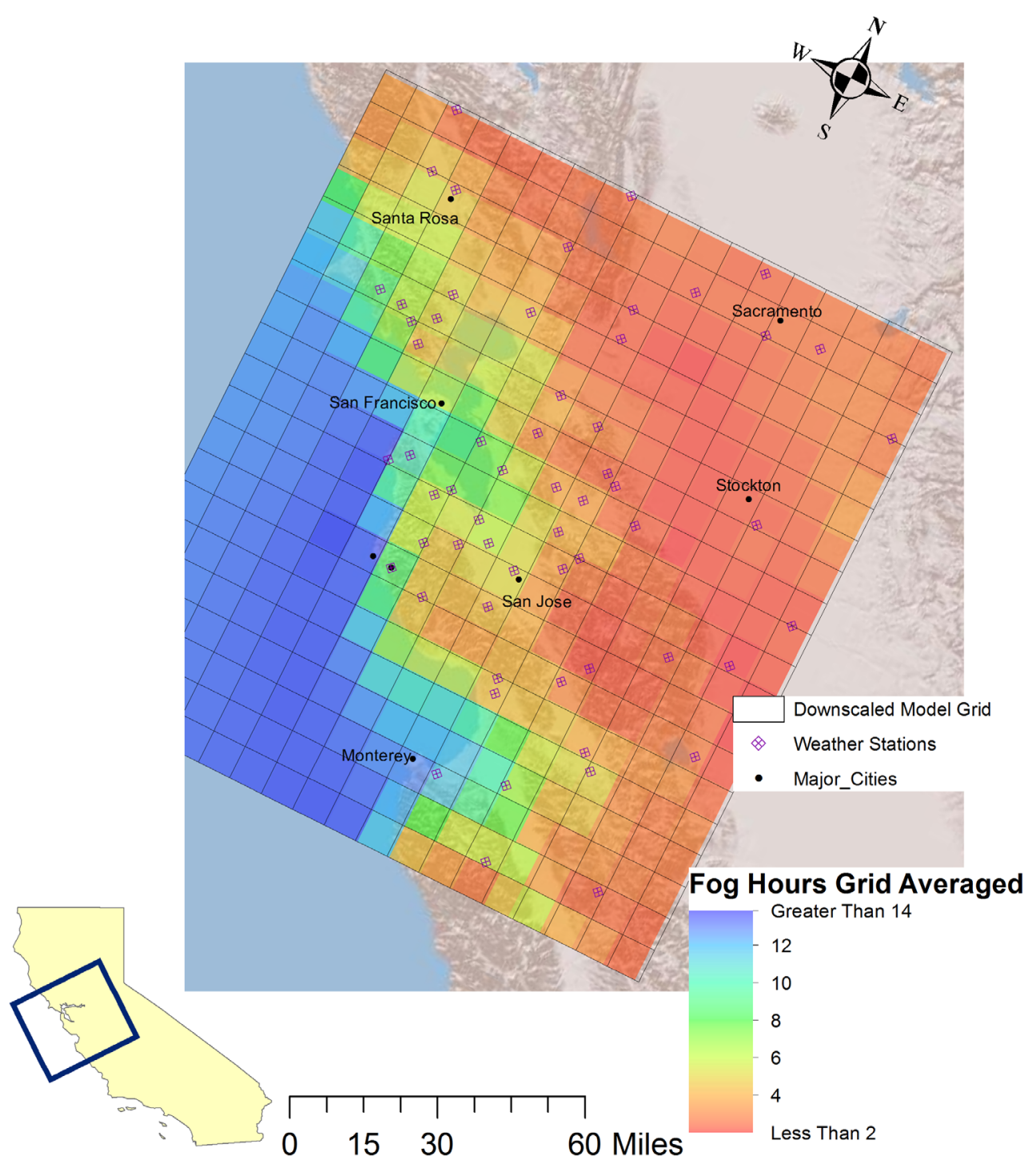

Reference Scale: 1:1,630,210 Basemap Credit: Copyright:@ 2014 Esri

Fig. 9 Fog hours averaged to the same resolution a downscaled CMIP5 data sets 


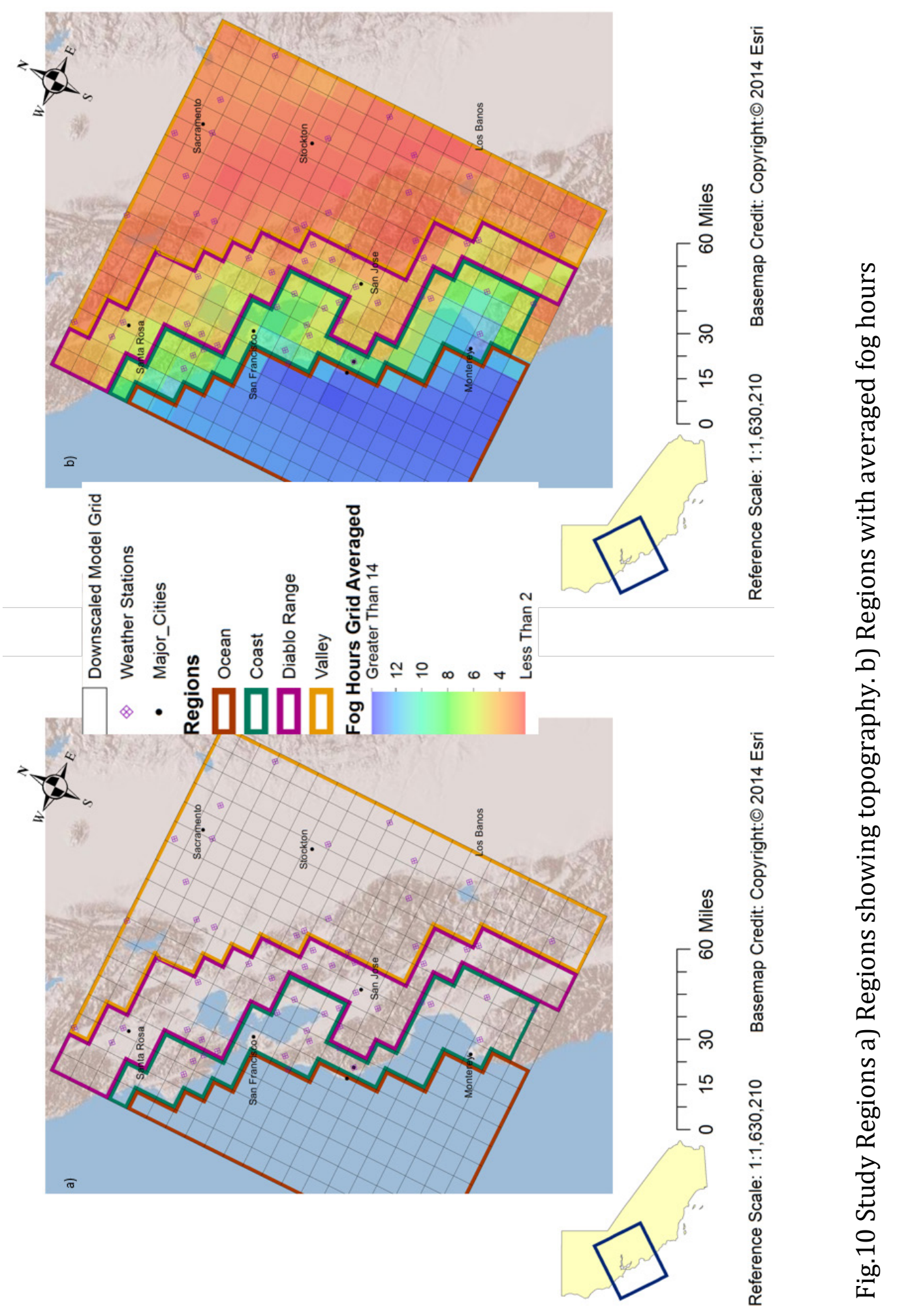


The western front of the Coast and Diablo ranges receive around six hours for fog per day, while the eastern front receives fewer than two. Station correlations were used as described above to group stations into three geographic regions. The boundaries of these regions were drawn along model grid lines using geographic features, along with the number of fog hours from Fig. 9. Fig. 10 shows the three regions created from station correlations and the fourth ocean region. Fig. 10a shows a clear view of underlying topography while Fig. 10b shows the fog hours within each region. Unlike the rest of the San Francisco Bay Area, the San Pablo Bay receives less fog and correlates better with the diablo range region, as is expected with the northwesterly winds driving the advection fog.

\section{c. Compare Station and Fog Data}

Using the sample tool from the spatial analyst toolbox in GIS (ESRI 2014), the number of fog hours at each station was found. A linear regression analysis was performed for each region on Tdiff and fog hours using equations from Taylor (1997) in Python.

Tdiff was interpolated to the coast region using the raster calculator in GIS (ESRI 2014) with Eq. 1.

$$
\text { Tdiff }_{\text {raster }}=\frac{\text { FogAvg }_{\text {raster }}-y_{\text {intercept }}}{\frac{\text { FogAvg }_{\text {point }}}{\text { TdiffObs }}}
$$

The equation of the best fit line $(y=m x+b)$ was used to create the above equation, where $y=F_{0 g} A v g_{\text {raster }}$ is the average fog raster shown in Fig. 9, $\mathrm{m}=\mathrm{FogAvg}_{\text {point }} /$ TdiffObs $_{\text {point }}$ is the slope of the best fit line from linear 
regression analysis of station data (FogAvg_point is the average number of fog hours at each station and TdiffObs point $_{\text {is }}$ is the observed temperature difference at

each station) , and $\mathrm{b}=y_{\text {intercept }}$ is the $\mathrm{y}$ intercept from the linear regression analysis of station data. Interpolated Tdiff grid values were compared to station values; the y-intercept was adjusted within the standard error until Tdiff was reasonably close to station values.

\section{d. Downscaled Model Data}

The downscaled data consisted of 14 models with varying numbers of ensemble runs for each model. The ensemble runs were averaged together for each model to create a model average. Each model average was then separated into the four regions and averaged over the area (latitude and longitude) to obtain a timeseries average for each model. This process was used for both RCP scenarios and both variables. Tdiff was then calculated, as above, for each region. The multi-model mean was calculated by summing the time-series average for each model then dividing by the number of models to reduce biases stemming from varying ensemble runs. This process was performed on Tmax, Tmin, and Tdiff for each of the four regions in both RCP scenarios.

The multi-model means were decadally averaged and trends found by a linear regression analysis using Scipy 0.16.1-1 library for Python (Walt et al. 2011). The decadal Tdiff values for 2010 were compared to observational values at each grid point and a difference calculated between them. The difference was then subtracted from all model data between 2010 and 2090. 


\section{e. Projecting Changes in Fog}

Fog projections were calculated two ways. First, looking at the regional average in time, and second looking at each grid point in time to see spatial changes. The projections for the entire coast region was calculated using the following relationship:

$$
\frac{\text { Fog }_{\text {Future }}}{\Delta \text { time }}=\frac{\text { FogAvg }_{\text {raster }}}{\text { Tdiff }_{\text {raster }}} * \frac{\Delta \text { Tdiff }}{\text { model }}
$$

The error was calculated using equation 3.43 in Taylor (1997) (Eq. 3 here), where $q$ is the product of Eq. 2, $x$ is the first term in Eq. 2, $y$ is the second term in Eq. 2, $\delta x$ is the standard error of $\mathrm{x}$, and $\delta y$ is the standard error of $\mathrm{y}$.

$$
\delta q \approx\left|\frac{\partial q}{\partial x}\right| \delta x+\left|\frac{\partial q}{\partial y}\right| \delta y
$$

The spatial changes were calculated using the following formula:

$$
\Delta \text { Fog }_{\text {projected }}=\frac{\text { FogAvg }_{\text {raster }}}{\text { Tdiff }_{\text {raster }}} * \text { Tdiff } f_{\text {model }}-\text { FogAvg }_{\text {raster }}
$$

Projected changes in fog values for 2010 were examined to verify they were approximately zero (all values less than $10^{-15}$ ).

\section{Results}

\section{a. Observations}

The three geographic regions were constructed by examining station correlations. The valley region stations listed in Table $3 \mathrm{had}$ a correlation coefficient of 0.7 or higher except station RSPC1. This station is located near a grid line boundary that has correlation coefficients of 0.64 or greater. It showed a better 
relationship with the valley region than the diablo range region. The diablo range region's correlation coefficients (Table 4) ranged from 0.53 - 0.98 due to variations in elevation related to orographic effect. Similarly, the coast region (Table 5) ranged from $0.38-0.93$. The lowest coefficients were associated with the KHAF station, which is located less than 1 mile inland from the Pacific Ocean and less than 100 feet above sea level (Google Inc. 2012), unlike most other stations, which are further inland and at varying elevations due to the orographic effects along the California coast. With over 1800 measurements at each station, all correlation coefficients for each region were highly significant. 


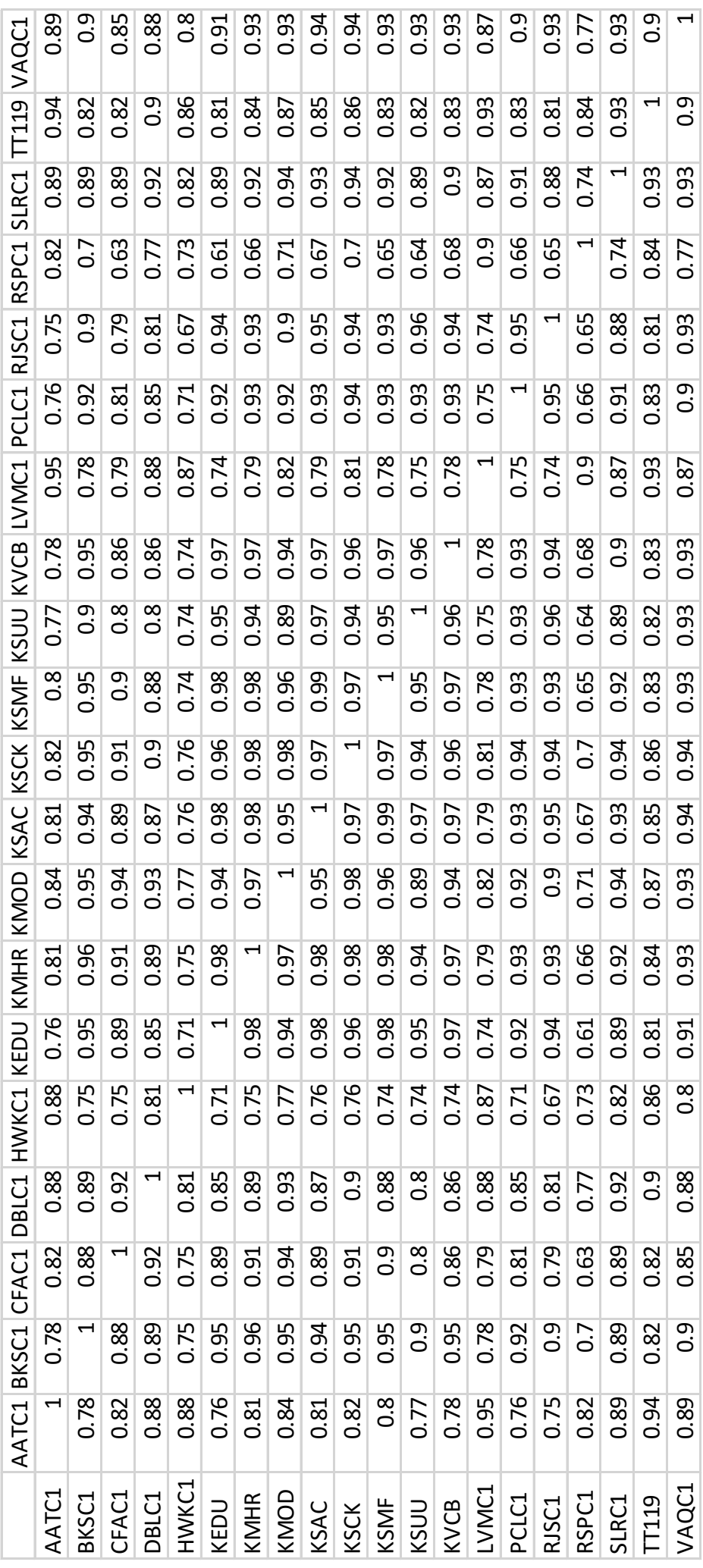




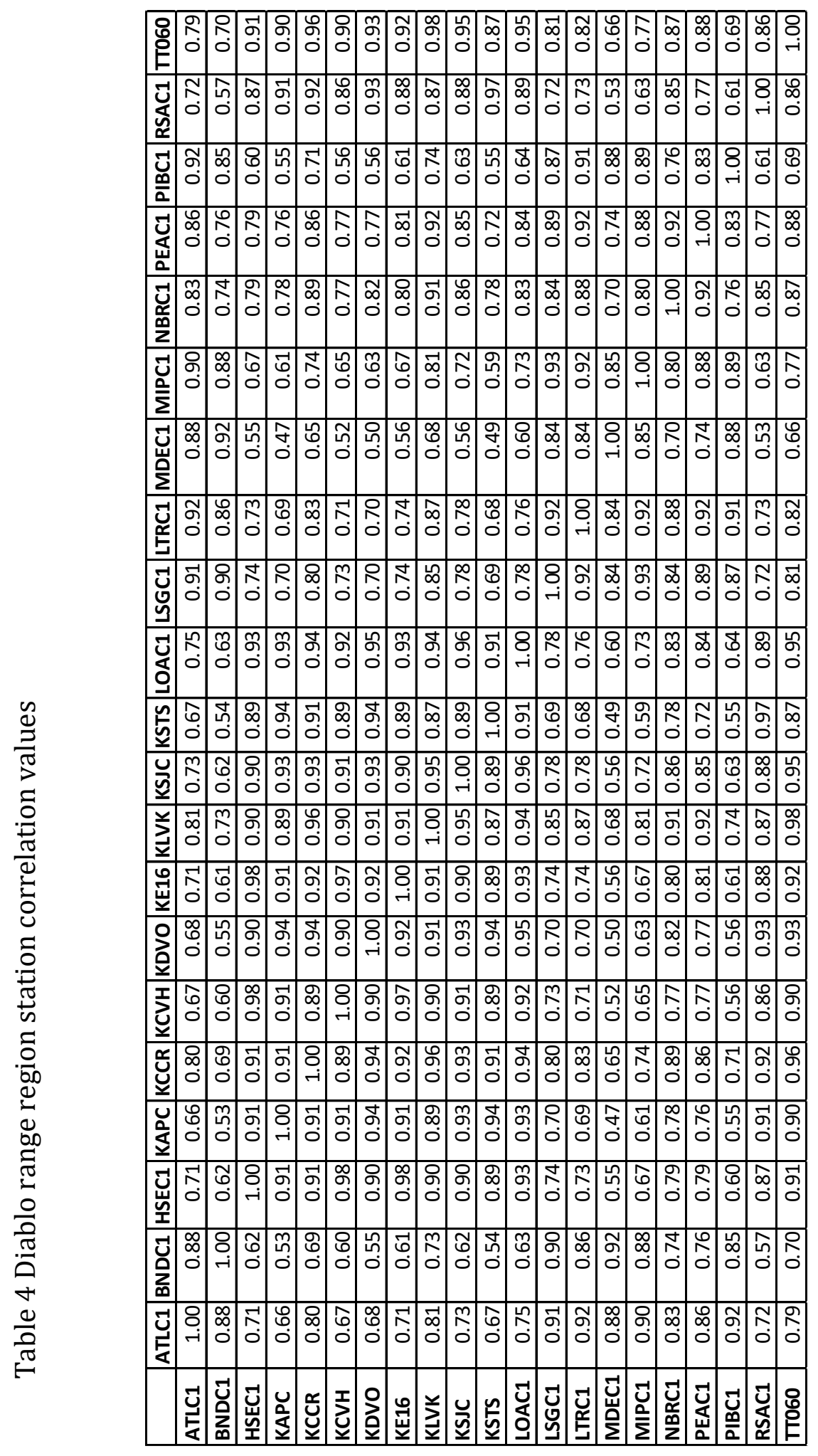




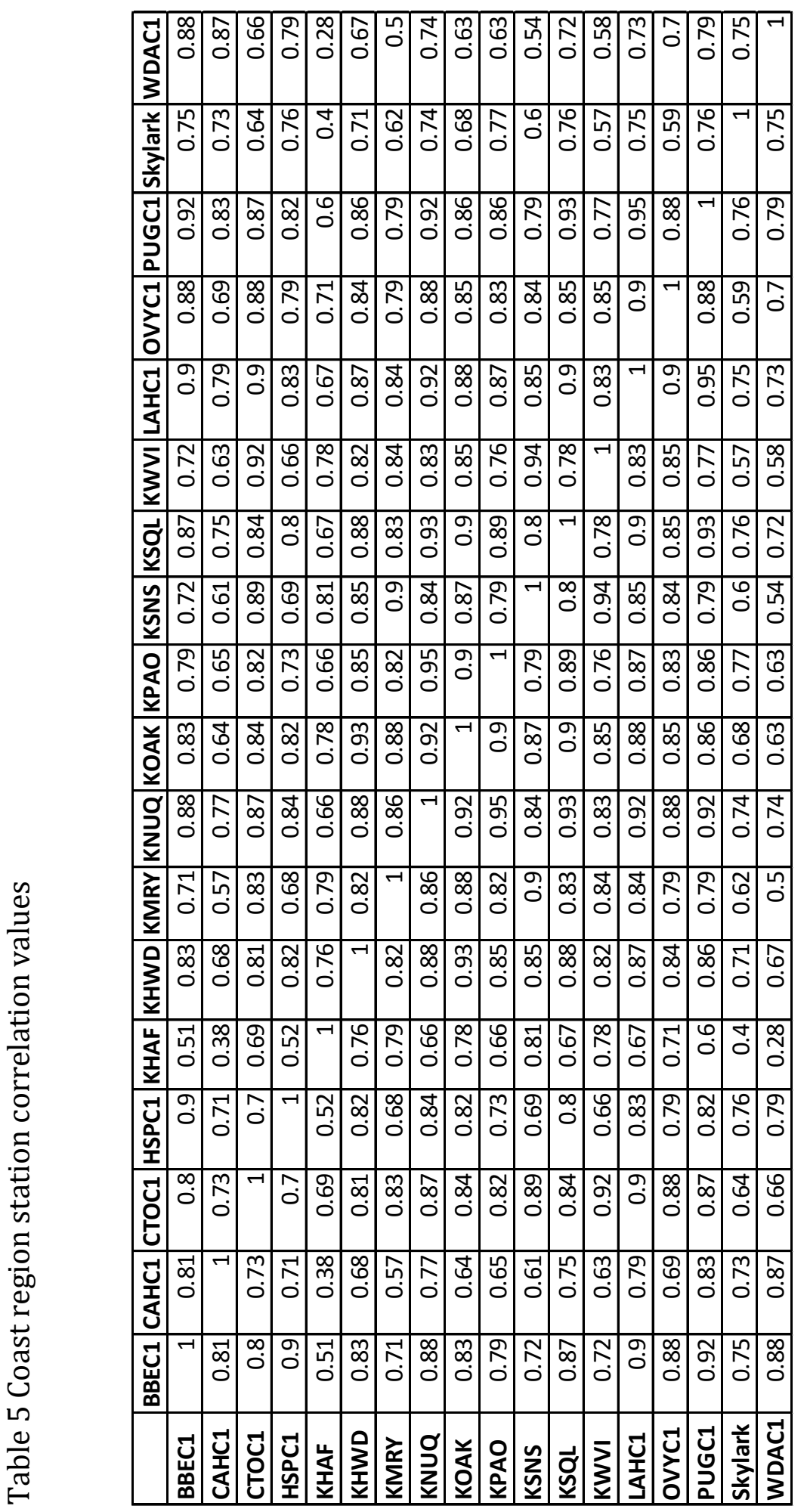


Fig. 11 shows the number of fog hours, which were averaged over the downscaled grid and the diurnal temperature difference for each weather station. Within each region, temperature differences are similar with variations due to elevation changes. The coast region has predominantly a $10^{\circ} \mathrm{F}-20^{\circ} \mathrm{F}$ diurnal temperature difference. The diablo range region predominantly has a $20^{\circ} \mathrm{F}-30^{\circ} \mathrm{F}$ difference, and the valley region has a difference of $20^{\circ} \mathrm{F}$ or more. Each region also shows a similar number of fog hours. KHAF (Half Moon Bay) has a diurnal temperature difference of approximately $7^{\circ} \mathrm{F}$ and falls along the grid line between the ocean region and the coast region. The ocean region has greater than 12 hours of fog per day; however, no temperature measurements over the ocean region were obtained in this study, and therefore excluded from fog projections. The coast region has between six and twelve hours of fog per day, the diablo region has between six and four hours per day, and the valley region has predominately less than two hours per day. Fig 12 shows the correlation between the diurnal temperature difference and the number of fog hours. There is no statistically significant relationship between fog and temperature difference in the diablo region nor the valley region; thus, they were excluded from fog projections in this study. While these two regions play a role in the inland intrusion of fog (Palmer 1917), which likely affects the number of fog hours on the coast, the West to East temperature difference is outside the scope of this study. 


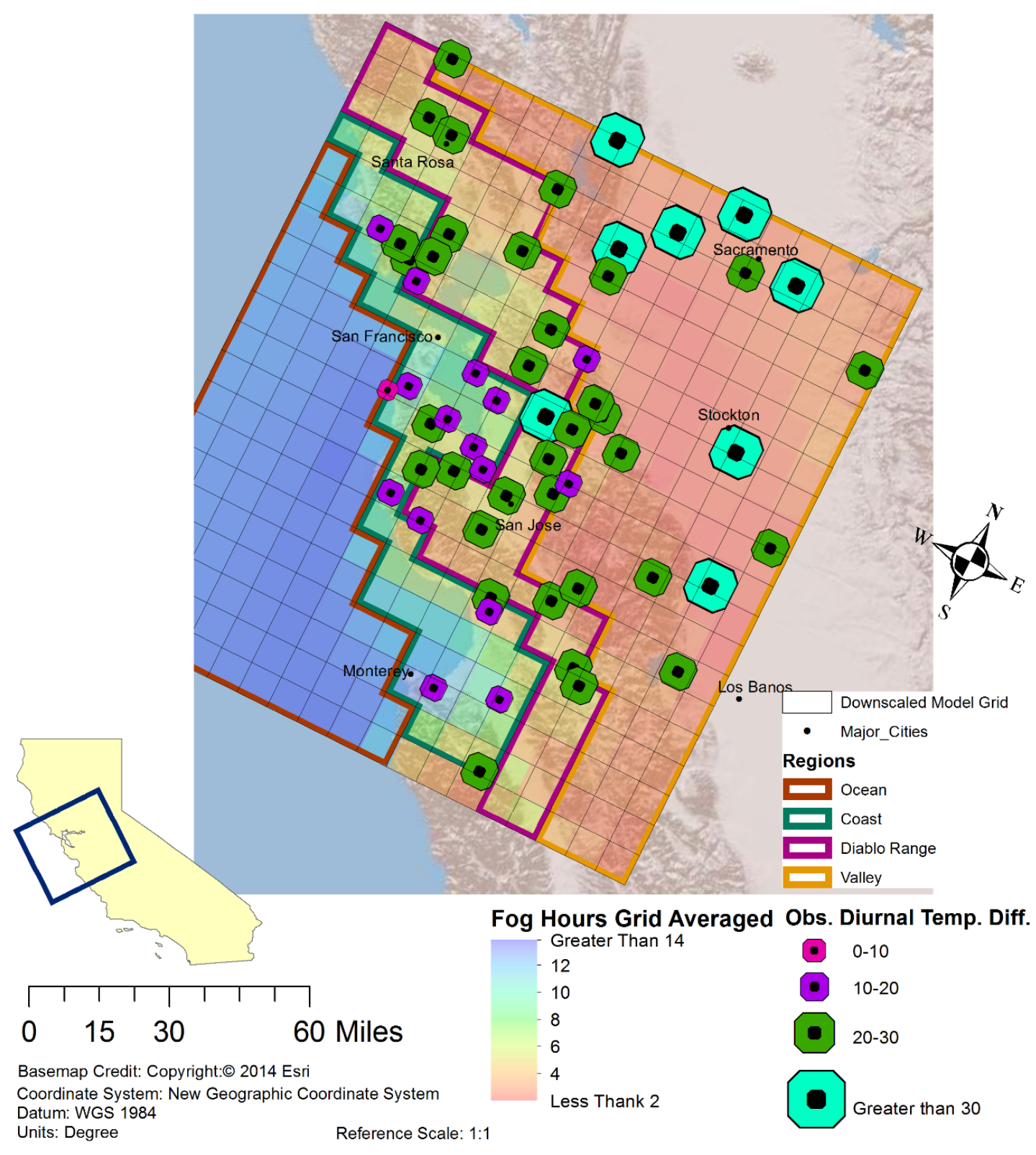

Fig. 11 Average fog hours and diurnal temperature difference. Dots are the diurnal temperature difference at each MesoWest station and the shaded background is the number of fog hours averaged over the climate model grid 


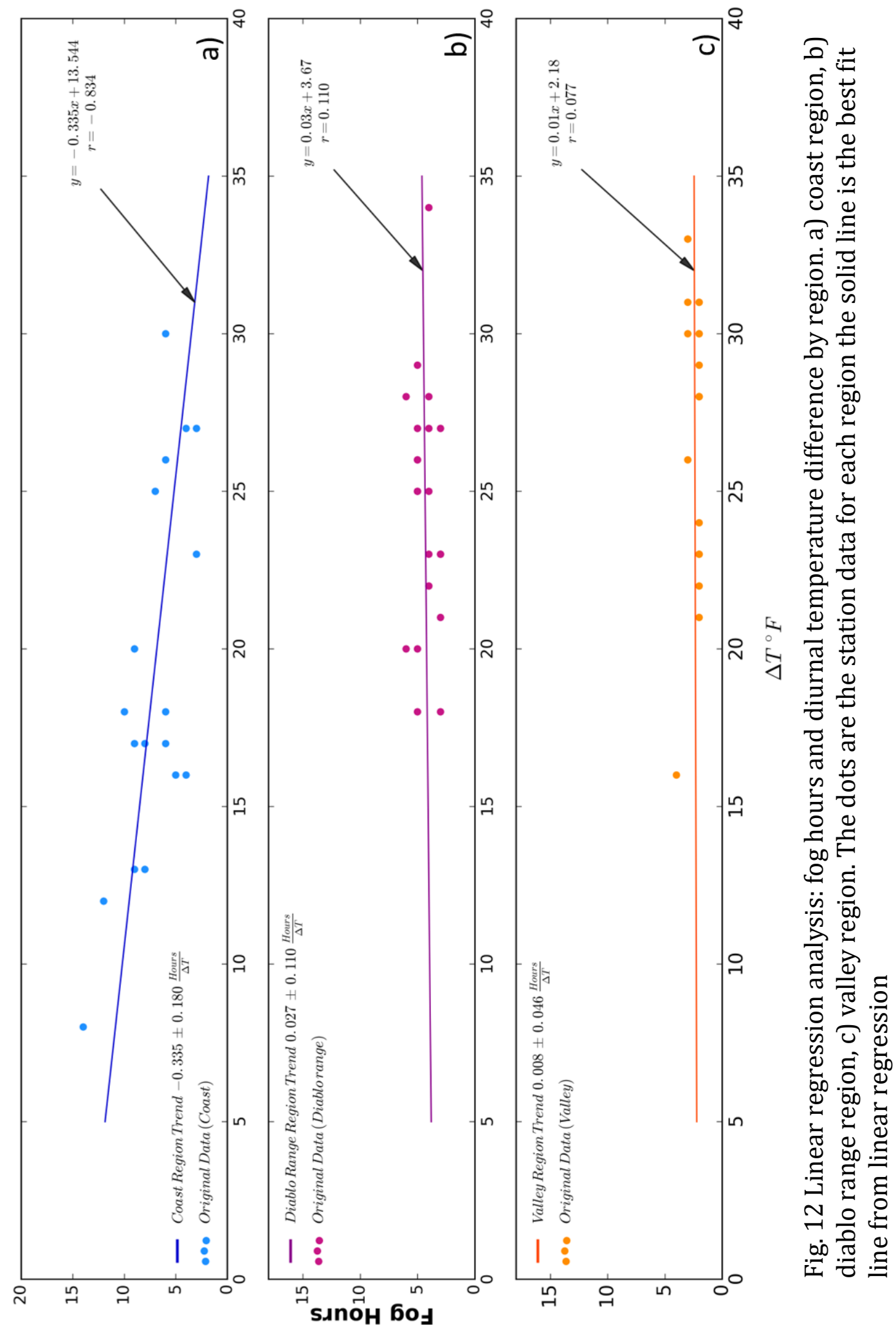


The coast region shows an anti-correlation between the diurnal temperature difference and the number of fog hours. This region shows a decrease of $0.335 \pm$ 0.110 hours of fog per degree of temperature difference $\left({ }^{\circ} \mathrm{F}\right)$ at the $95 \%$ confidence level. The trend (FogAvg point $_{\text {TdiffObs }}$ point), shown in Fig. 12a, was used to interpolate the temperature difference to all grid points, as described above.

Fig. 13 shows the correlations in coast region, similar to Fig. 12, with the best fit line (solid blue). The black dashed line is the best fit plus/minus $\sigma_{y}$, the standard error in $y$ at the $95 \%$ confidence level. The red dash-dot line is the line which was most realistic when interpolated and compared to weather station measurements (see Fig. 14). Fig. 14 shows the temperature differences, which were interpolated to the model grid using the linear regression from Fig. 13. The interpolation with the best fit line (solid blue) from Fig. 13 is shown in Fig. 14a. Note the area near Monterey the KMRY station has a temperature difference of $10^{\circ} \mathrm{F}-15^{\circ} \mathrm{F}$ yet the interpolation suggests less than a $10^{\circ} \mathrm{F}$ difference, which is not realistic. Near Half Moon Bay this interpolation shows $10^{\circ} \mathrm{F}-15^{\circ} \mathrm{F}$ difference but the HSPC1 station shows a $15^{\circ} \mathrm{F}-20^{\circ} \mathrm{F}$ difference. The HSPC1 station is a reasonable approximation for the area due to the elevation over most of the grid points in the area. The current interpolation does not reflect the geographic relief in this area. Also further north along the coast near Santa Rosa the topography lends its self to larger temperature differences. Fig. 14b shows the new interpolation using a y-intercept of 16. 

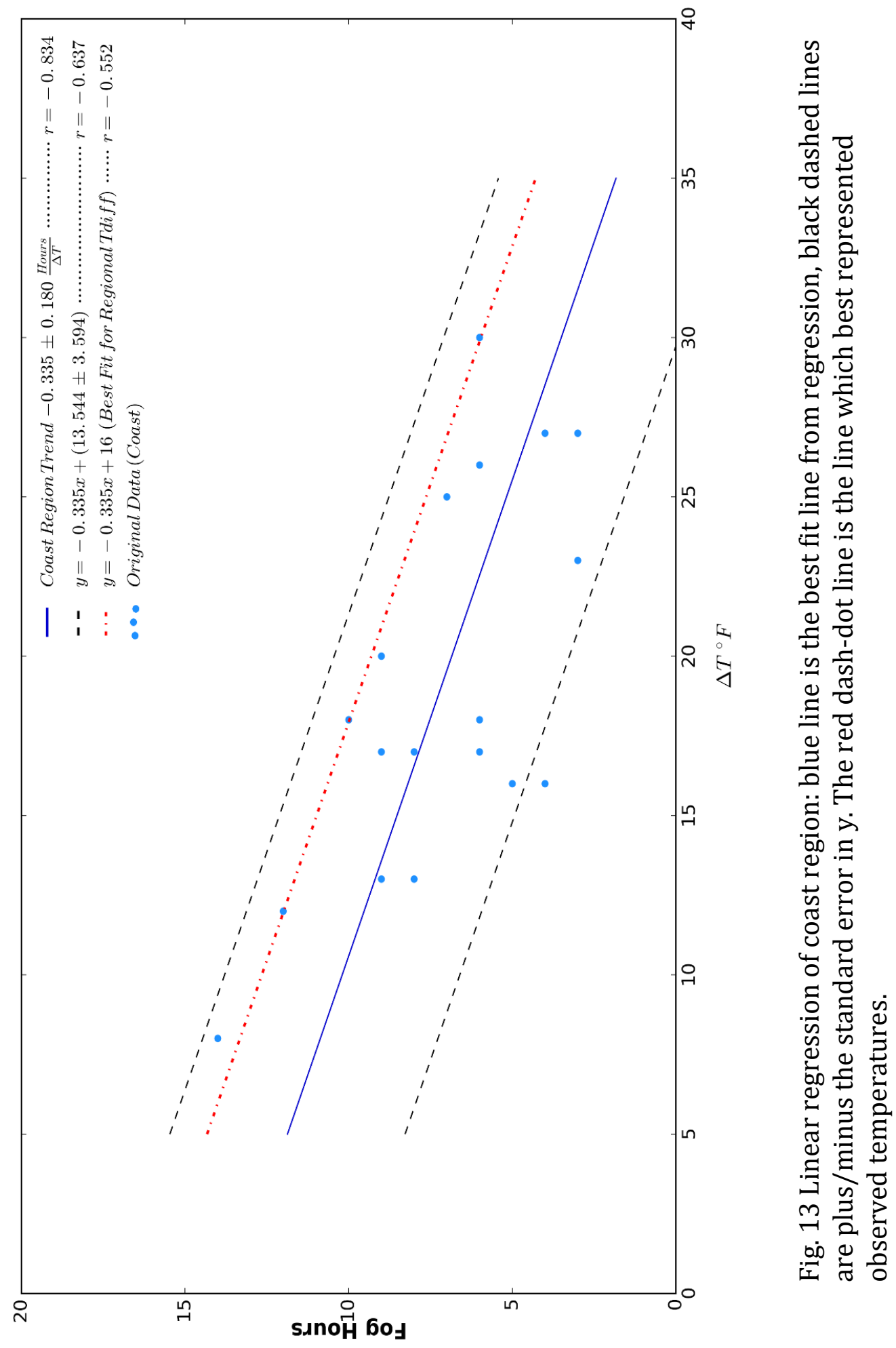

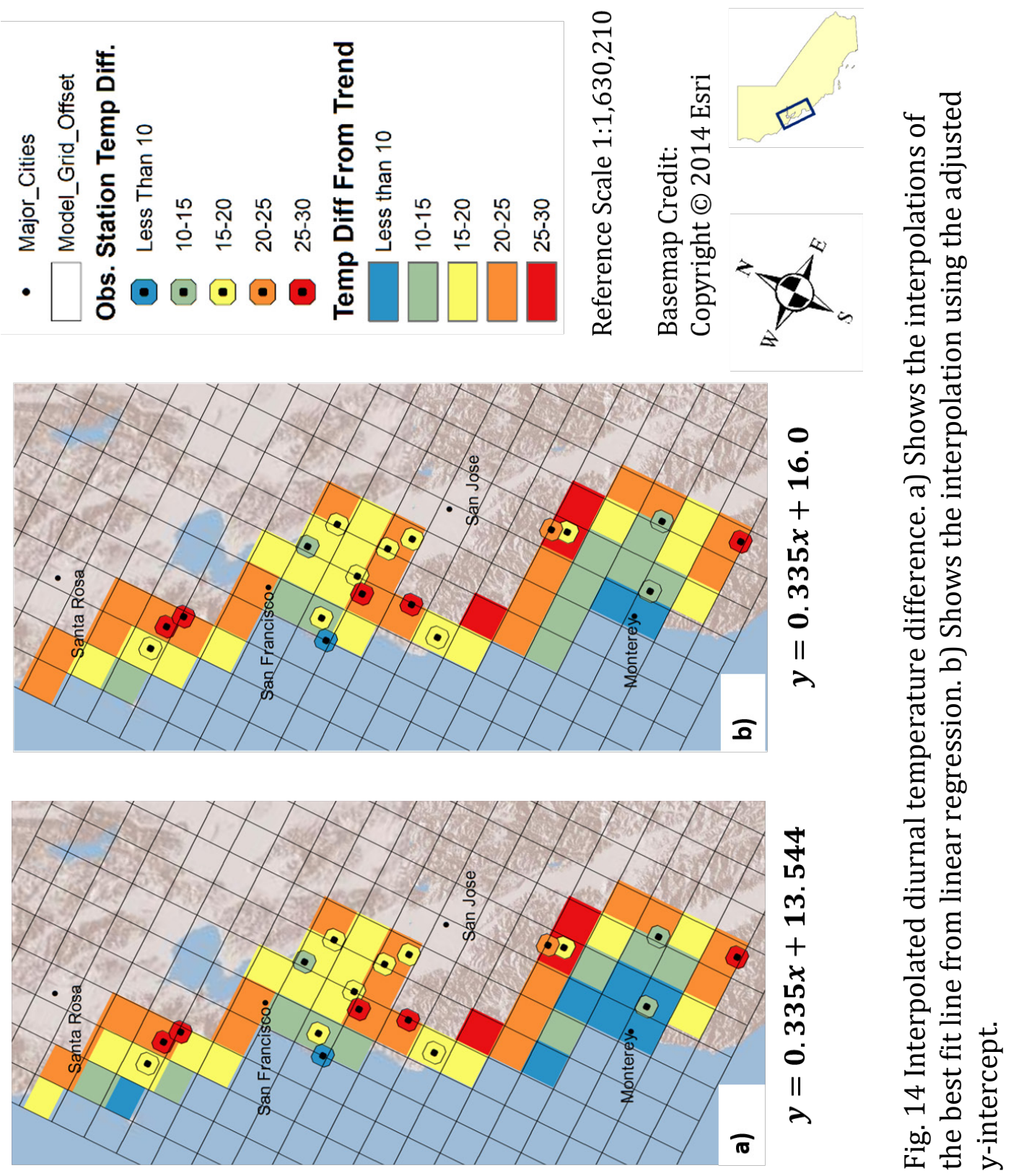
Monterey now aligns with the observed temperature difference. Moreover, the areas near Half Moon Bay and Santa Rosa are also more in alignment with climatological diurnal temperature differences. Climatological monthly averaged daily highs and lows were examined for cities within the modified grid points using http://www.intellicast.com. Using the intellicast.com values the summer average temperature difference was calculated and compared with new values. The new interpolation matched most climatological values within a few degrees; sometimes falling on the other side of a category break in the figures like station HSPC1 near Half Moon Bay. Various other cities were also checked within the region with similar results.

\section{b. Downscaled Climate Models}

Fig. 15 displays the ensemble averages from the 14 models and the multimodel mean for the minimum temperatures in the RCP 4.5 scenario. This Fig. also shows how many ensemble runs each model had. The mri-cgcm3 and the gfdlesm2g models had the coolest temperatures; while the micro-esm, cansm2, and micro-esm-chem models where the warmest. The central valley region (Fig. 15) is the most variable of the four regions. The ocean, coastal and diablo regions (Fig. $15 \mathrm{a}, 15 \mathrm{~b}$, and $15 \mathrm{c}$ respectively) have a dichotomy about the mean beginning around 2040. This dichotomy is present in the maximum temperatures but much less obvious than in the minimum temperatures. Figures for the maximum temperature in RCP 4.5, both max and min temperatures for RCP8.5, and the diurnal temperature 
difference for all models in both scenarios can be found in appendix A. The warmest and coolest models for the figures in the appendix are the same as noted above.

Fig. 16 shows the multi-model decadal means for the coast region. Both RCP 4.5 and RCP 8.5 show an increase in maximum and minimum temperatures (Fig. 16a and 16b). RCP 4.5 shows the maximum temperatures increasing at a rate of $0.045 \pm$ $0.0039^{\circ} \mathrm{F} \cdot$ Decade $^{-1}$ and the minimum temperature increasing at a rate of $0.0388 \pm$ $0.0034^{\circ} \mathrm{F} \cdot$ Decade $^{-1}$. In RCP 4.5 the maximum and minimum temperatures are increasing at similar rates with the maximum temperature increasing slightly faster. The diurnal temperature difference for RCP 4.5, shown in Fig. 16c, is increasing at a very slow rate of $0.0037 \pm 0.0019^{\circ} \mathrm{F} \cdot$ Decade $^{-1}$ with almost a $0.5^{\circ} \mathrm{F}$ increase in the diurnal temperature difference by the turn of the century. The RCP 8.5 scenario also shows the maximum and minimum temperature increasing nearly the same rate (see Fig. 16a and 16b). The maximum temperature is increasing at a rate of $0.0725 \pm 0.0094{ }^{\circ} \mathrm{F} \cdot$ Decade $^{-1}$ and the minimum temperature is increasing at a rate of $0.0704 \pm 0.0113^{\circ} \mathrm{F} \cdot$ Decade $^{-1}$. The diurnal temperature difference for RCP 8.5 (Fig. 16c) is not statistically significant with a rate of $0.0021 \pm 0.0024^{\circ} \mathrm{F} \cdot$ Decade $^{-1}$. For both RCP scenarios the diurnal temperature difference shown in Fig. 16c begins to increase around 2000 and then begins to decrease around 2060. 


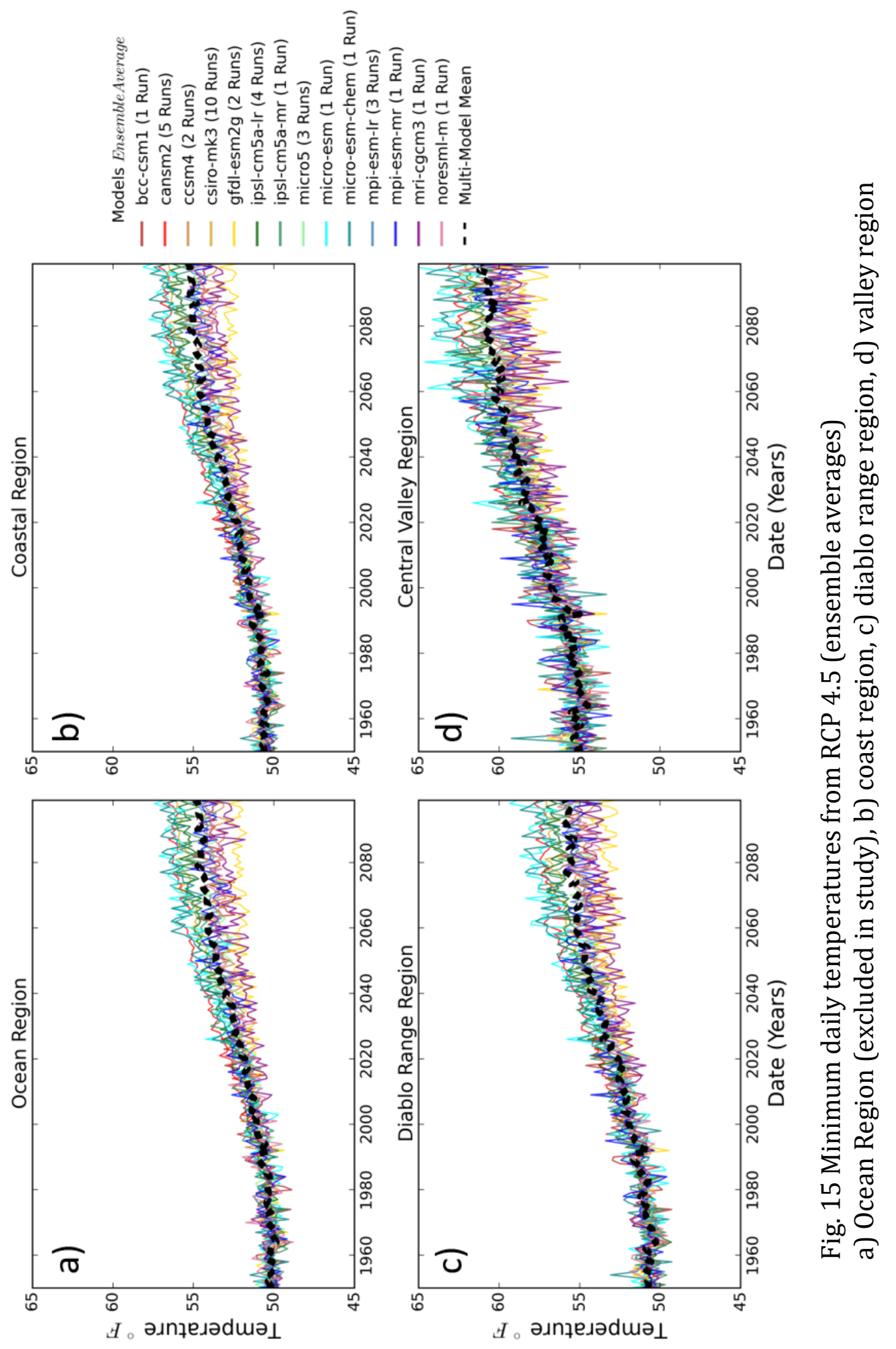




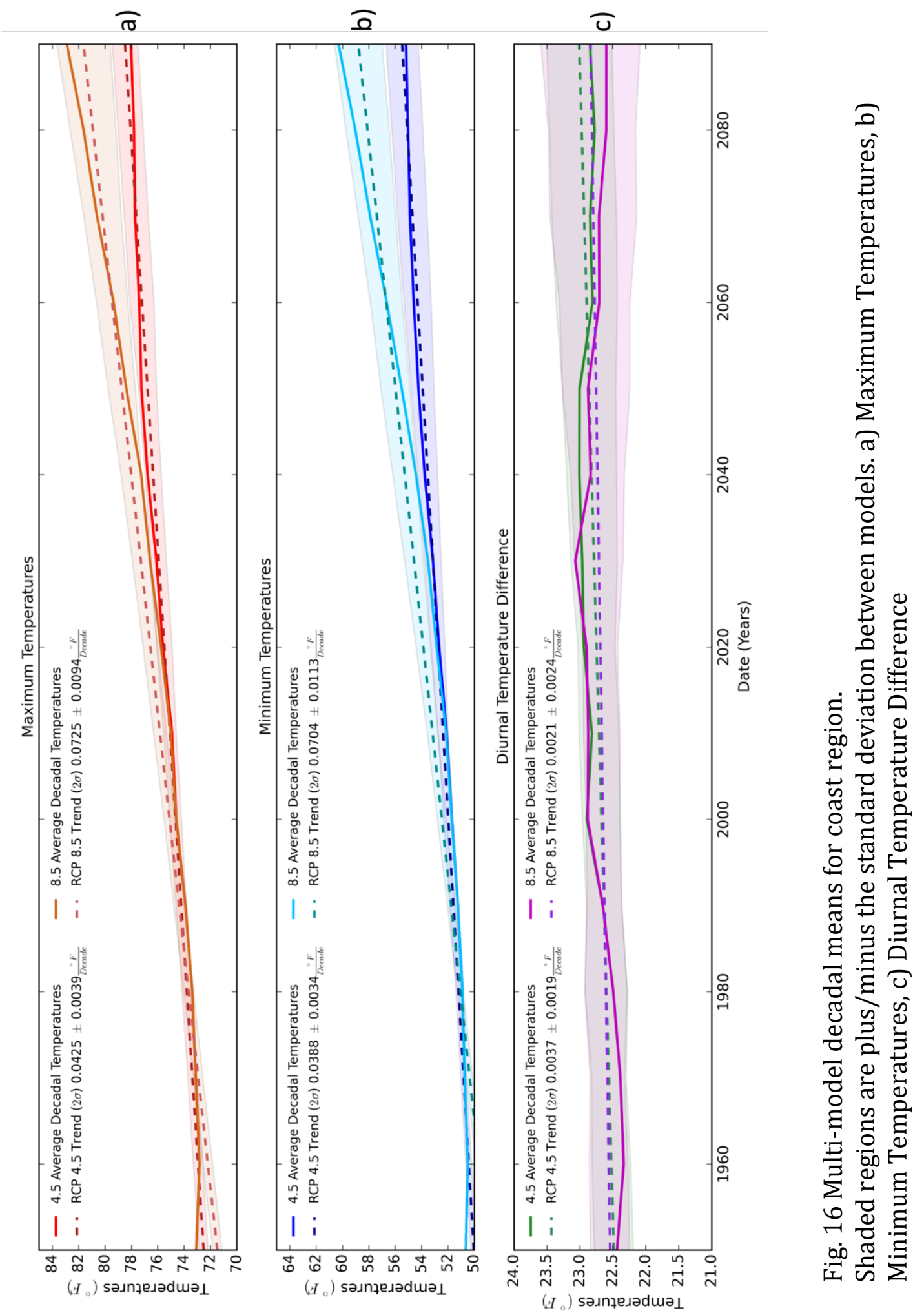


The diurnal temperature difference from the models was also calculated on a grid by grid basis. The model average for the 2010 decade was compared to the interpolated observations (shown in Fig. 14b), there were substantial differences in both the RCP scenarios. Fig. 17 shows the difference between the observations and RCP 4.5 (Fig. 17a) and RCP 8.5 (Fig. 17b). The differences are similar, as expected from Fig. 16, which shows the diurnal temperature difference, between RCP 4.5 and RCP 8.5, are almost the same as the 2010 values. However, there are slight differences, for example, the Monterey grid point and a few of the grid points near Santa Rosa. The models have much larger temperature differences than observed values. In the north near Santa Rosa there is greater than a $20^{\circ} \mathrm{F}$ difference while there are smaller differences near San Francisco where the model is more than $10^{\circ} \mathrm{F}$ cooler than observations. These values were subtracted from the model temperature differences so temperature differences matched those of 2010 observations. 


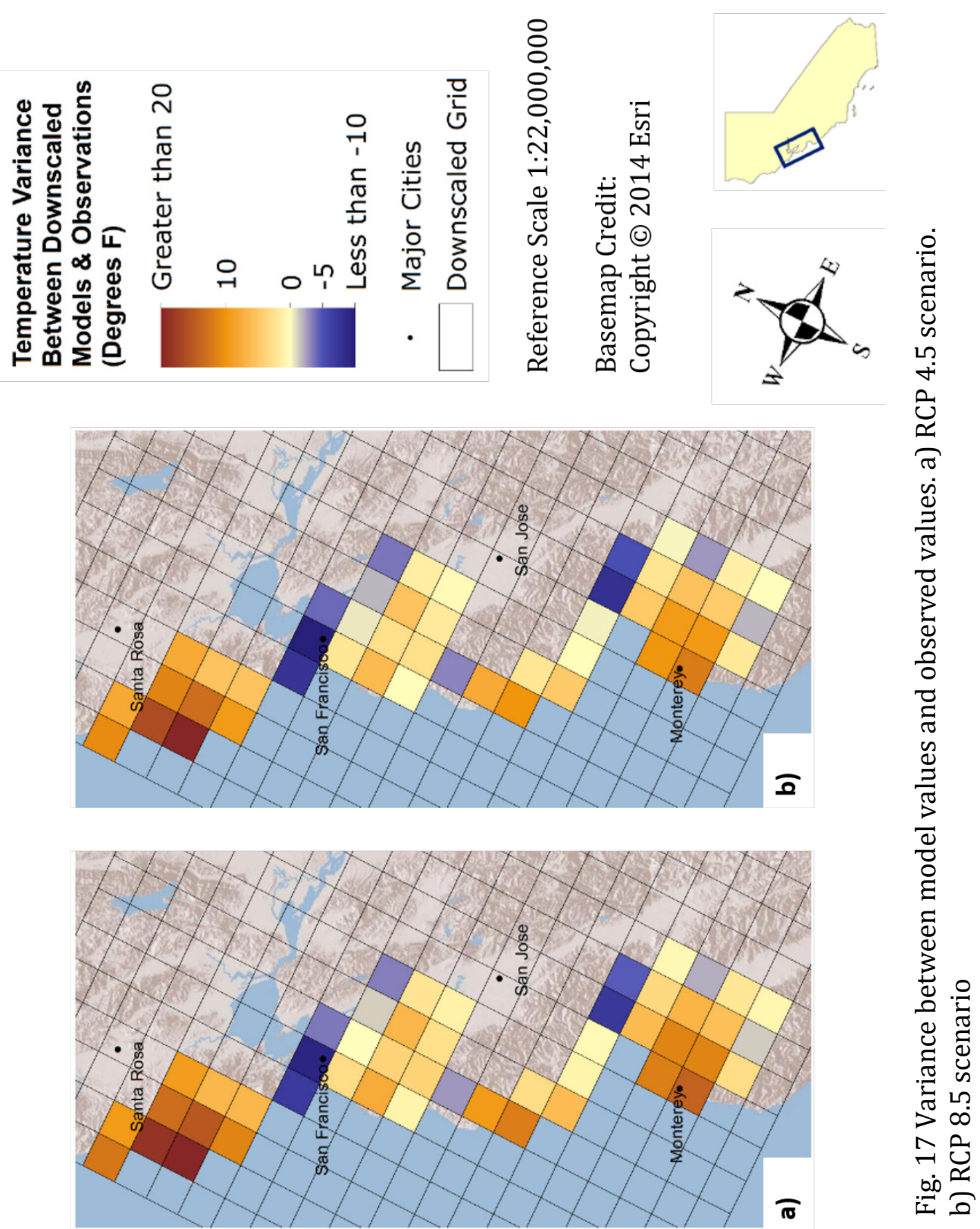




\section{c. Fog Prediction}

The changes to fog hours in the future was looked at as a region, as a whole, and at the grid point level. Considering the entire region, both scenarios show decreases in fog but, neither is statistically significant. Fig. 18 shows the predicted change in fog hours for the coast region. Both RCP 4.5 and RCP 8.5 change less than a hundredth of an hour by the turn of the century.

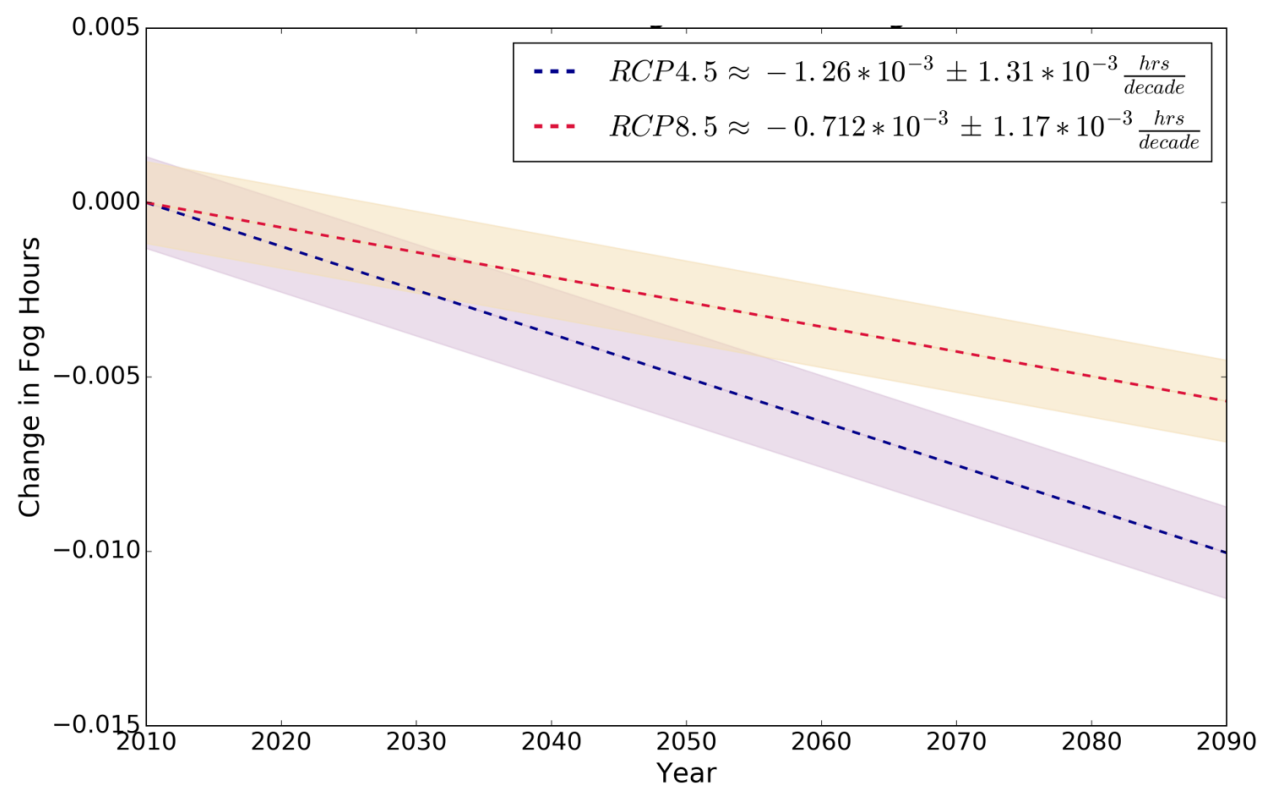

Fig. 18 Regional trend of the change in number of fog hours

However, looking at the spatial extent of the changes in fog hours, a different story is portrayed. Fig. 19 shows how fog hours are likely to change each decade, per grid point, for the RCP 4.5 scenario. 

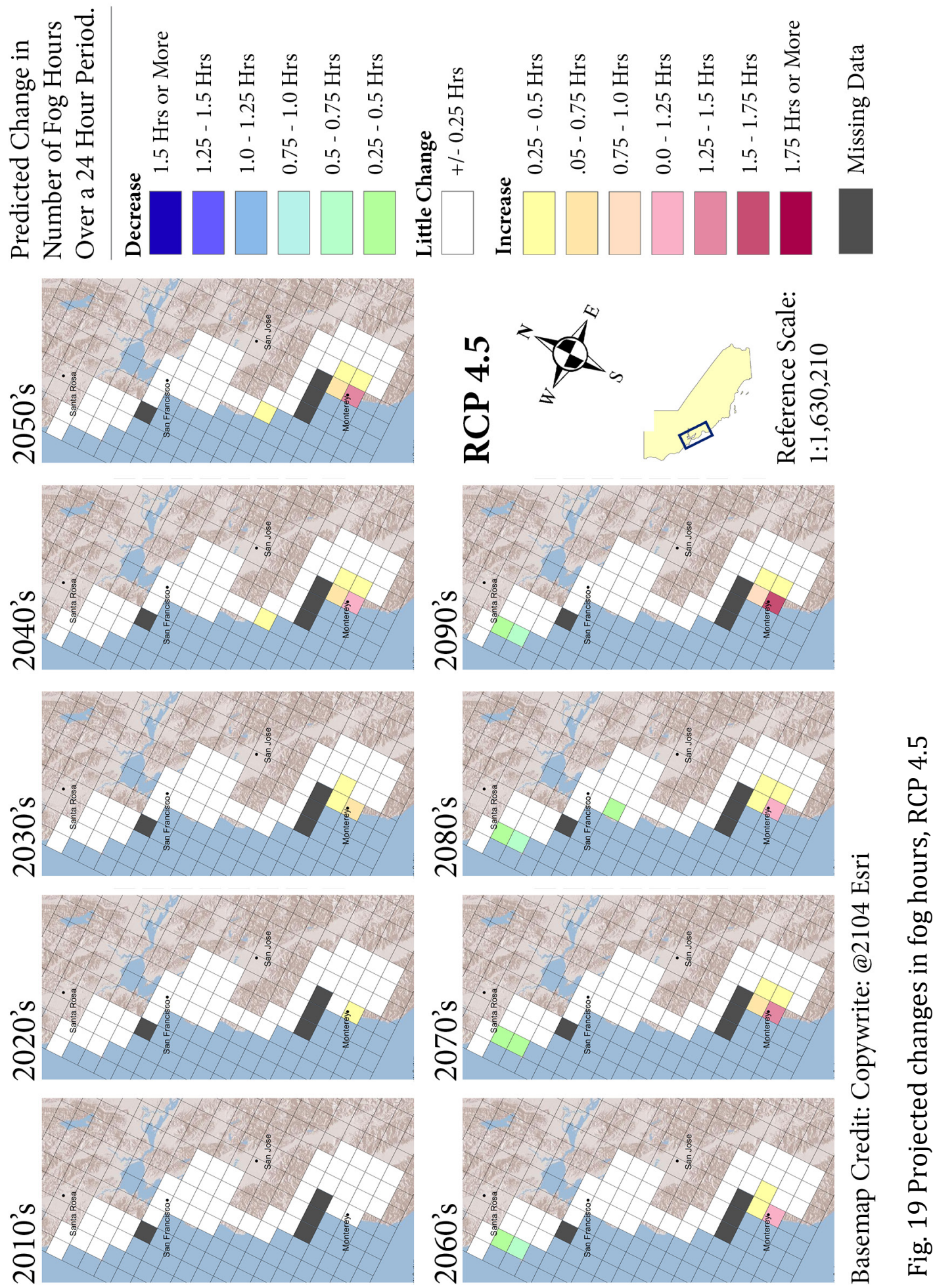

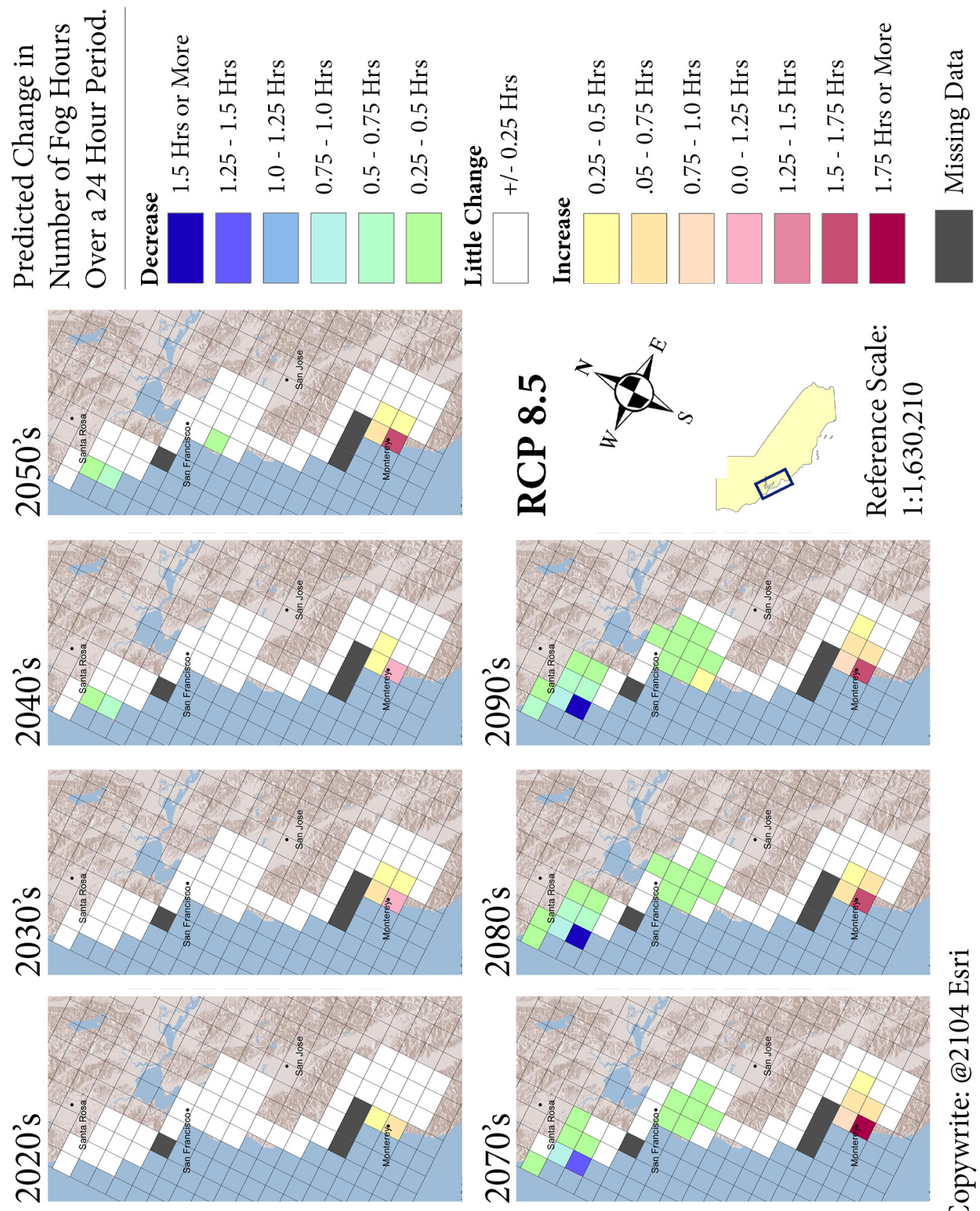

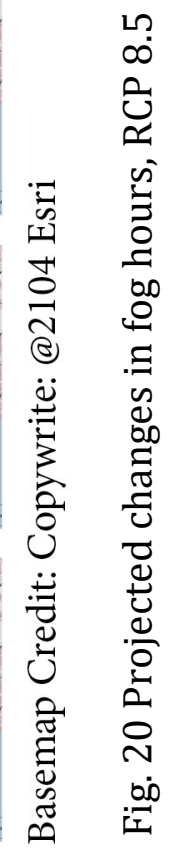


RCP 4.5 shows many areas with little to no change in fog hours

( \pm 15 minutes), but other areas such as Monterey show an increase of an hour and a half or more, yet areas to the north near Santa Rosa show a decrease of a half an hour or more. RCP 8.5, shown in Fig. 20, also displays an increase in fog hours for the Monterey area of a half an hour to an hour and a half or more. This scenario also shows a decrease in the San Francisco Bay Area of fifteen to thirty minutes except the Half Moon Bay Area with is showing an increase of the same amount. Areas in the North towards Santa Rosa are also showing a decrease of 15 minutes or more with Point Reyes showing a decrease of an hour and a half or more.

\section{Conclusion}

This study examined the relationship between diurnal temperature differences and number of fog hours using observations and downscaled climate models to estimate the effects of climate change on the number of fog hours. Looking at two RCP scenarios (RCP 4.5 and RCP 8.5) it was shown that most of the California's central coast will likely see minimal changes ( \pm 15 minutes) through the turn of the century. However, places such as Point Reyes may see a larger decrease of as much as an hour and a half in fog hours while Monterey may see an increase by more than an hour and a half (see Fig. 19 and 20). Studies by Schwartz et al. (2014) and Johnstone and Dawson (2010) have all showed a slight decrease in fog over the past 50 years. Schwartz et al. (2014) found a five percent decrease (1950-2009) in summertime coastal low clouds when looking at the average of 19 airports. Johnstone and Dawson (2010) found a distinct trend in the third principle 
component of maximum temperatures time-series, suggesting a decrease in fog frequency between 1901 and 2008. The timing of an increase or decrease in the fog hours was not part of this study, but would likely have implications on transportation, energy use, human health, and coastal ecosystems. If the increase in fog hours occurs during daytime hours, extending the morning fog, coastal airports will likely see longer delays affecting flights across the country, energy use may be lessened in coastal communities, and there may be fewer heat-related emergency room visits. However, if a decrease occurs during daytime hours, shortening or eliminating morning fog, the coastal temperatures will likely increase resulting in increased energy use, increased irrigation of coastal crops, and an increase in the number of heat-related emergency room visits.

\section{a. Uncertainties}

Uncertainties in this data set stem from the type of data available, along with uncertainties in measurements from instrumentation and uncertainties in models from atmospheric processes, which are not well understood and computing limitations. Observational data used in this study was collected over a single summer, from June to August in 2014, which was an atypical year. 2014 was part of the 2012-2014 California drought, which was the worst short-term drought in the last thousand years (Griffin and Anchukaitis 2014) and broke temperature records by $1.1^{\circ} \mathrm{F}$ for January-August records (NOAA National Centers for Environmental Information 2014). The fog data set on the other hand is comprised of 11 years' worth of data from June to September from 1999-2009, which was used as a 
climatological average of fog hours. Had 2014 been a more average year, there would be fewer uncertainties with this approach.

The temperature data from stations are at different elevations above sea level, resulting in some being above the inversion height at times, which would increase the diurnal temperature difference. Additionally, temperature was used in this study instead of potential temperature, creating further uncertainties from elevated stations.

MesoWest performs basic quality control checks; however, instruments always have inherent uncertainties in their measurements. Similarly, satellite images and the post processing of those images also have additional uncertainties. Additionally, there were limited station observations along the coast, biasing my analysis to temperature patterns inland.

\section{b. Future Work}

Further improvements in fog prediction could be achieved by including a longer observational period with finer spatial resolution. A finer spatial resolution can be obtained by including observations from all MesoWest networks, ocean buoy observations and lighthouse or lightship observations. Additionally, converting the temperature values to potential temperature could improve station correlation processing. Obtaining new satellite records for the same observational period should provide a better relationship. In addition to using and/or recreating the algorithm used by Combs et al. $(2004,2010)$ to process GOES-West images, adding new imagery from GOES-R Advanced Baseline Imager and utilizing the Low Cloud 
and Fog product (GOES-R Series Program Office) will provide an improved look at fog data and allow for comparisons between fog algorithms and observations. Additionally, looking at the east-west temperature gradient and sea surface temperatures may shed light on the extent of the fog intrusion. 


\section{References}

Ahrens, C. D., 2011: Essentials of meteorology: an invitation to the atmosphere. 6th ed. Cengage Learning, $506 \mathrm{pp}$.

American Meteorological Society, 2012: Fog - AMS Glossary. Available online at http://glossary.ametsoc.org/wiki/Fog (Accessed March 15, 2016).

Burgess, S. S. O., and T. E. Dawson, 2004: The contribution of fog to the water relations of Sequoia sempervirens (D. Don): foliar uptake and prevention of dehydration. Plant Cell Environ., 27, 1023-1034.

California Landscape Conservation Cooperative, Preliminary Summertime Fog Frequency for the North and Central California Coast for 1999-2009| California Climate Commons. http://climate.calcommons.org/datasets/summertime-fog (Accessed February 28, 2016).

Clark, D. A., and F. W. Wilson, 1996: The marine stratus initiative at San Francisco International Airport. Lincoln Laboratory, Massachusetts Institute of Technology.

Combs, C. L., W. Blier, W. Strach, and M. DeMaria, 2004: Exploring the timing of fog formation and dissipation over San Francisco Bay Area using satellite cloud composites. Preprints, 13th Conf. on Satellite Meteorology and Oceanography, Norfolk, VA, Amer. Meteor. Soc., P4.12. [Available Online at https://ams.confex.com/ams/pdfpapers/78778.pdf.].

Combs, C. L., R. Mazur, J. Clark, M. Nordquist, and D. Molenar, 2010: An Effort to Improve Marine Stratus Forecasts Using Satellite Cloud Climatologies for the Eureka, CA Region. 17th Conf. on Satellite Meteorology and Oceanography, American Meteorlogical Society, Annapolis, MD, Amer. Meteor. Soc., P9.16. [Available online at https://ams.confex.com/ams/17Air17Sat9Coas/techprogram/paper_17386 4.htm].

Corbin, J. D., M. A. Thomsen, T. E. Dawson, and C. M. D’Antonio, 2005: Summer water use by California coastal prairie grasses: fog, drought, and community composition. Oecologia, 145, 511-521.

Dawson, T. E., 1998: Fog in the California redwood forest: ecosystem inputs and use by plants. Oecologia, 117, 476-485.

Dorman, C. E., J. F. Mejia, and D. Koračin, 2013: Impact of US west coastline inhomogeneity and synoptic forcing on winds, wind stress, and wind stress curl during upwelling season. J. Geophys. Res. Oceans, 118, 4036-4051. 
ESRI, 2014: ArcGIS Desktop Version 10.2.2. Environmental Systems Research Institute.

Federal Aviation Administration, 2016: Terminal Procedures and Diagrams - SFO. available online at http://aeronav.faa.gov/d-tpp/1603/00375ad.pdf (Accessed March 15, 2016).

García-Reyes, M., and J. L. Largier, 2012: Seasonality of coastal upwelling off central and northern California: New insights, including temporal and spatial variability. J. Geophys. Res. Oceans, 117, doi:10.1029/2011JC007629.

Gershunov, A., Z. Johnston, H. G. Margolis, and K. Guirguis, 2011: The California heat wave 2006 with impacts on statewide medical emergency: A space-time analysis. Geography Research Forum, 31, 6-31.

GOES-R Series Program Office, Future Capability Product - Low Cloud and Fog. GOES $R$,. http://www.goes-r.gov/products/opt2-low-cloud-fog.html (Accessed March 23, 2016).

Google, Inc., 2012: Google Earth, Version 6.2.2.6613.

Griffin, D., and K. J. Anchukaitis, 2014: How unusual is the 2012-2014 California drought? Geophys. Res. Lett., 41, 9017-9023.

Hartmann, D. L., M. E. Ockert-Bell, and M. L. Michelsen, 1992: The effect of cloud type on Earth's energy balance: Global analysis. J. Clim., 5, 1281-1304.

Hiatt, C., D. Fernandez, and C. Potter, 2012: Measurements of Fog Water Deposition on the California Central Coast. Atmospheric Clim. Sci., 02, 525-525, doi:10.4236/acs.2012.24047.

Horel, J., and Coauthors, 2002: Mesowest: Cooperative Mesonets in the Western United States. Bull. Am. Meteorol. Soc., 83, 211-225, doi:10.1175/15200477(2002)083<0211:MCMITW>2.3.C0;2.

Johnstone, J. A., and T. E. Dawson, 2010: Climatic context and ecological implications of summer fog decline in the coast redwood region. Proc. Natl. Acad. Sci., 107, 4533-4538, doi:10.1073/pnas.0915062107.

Koračin, D., J. Lewis, W. T. Thompson, C. E. Dorman, and J. A. Businger, 2001: Transition of stratus into fog along the California coast: Observations and modeling. J. Atmospheric Sci., 58, 1714-1731.

——, C. E. Dorman, J. M. Lewis, J. G. Hudson, E. M. Wilcox, and A. Torregrosa, 2014: Marine fog: A review. Atmospheric Res., 143, 142-175.

Leipper, D. F., 1994: Fog on the US west coast: A review. Bull. Am. Meteorol. Soc., 75, 229-240. 
Maurer, E. P., L. Brekke, T. Pruitt, and P. B. Duffy, 2007: Fine-resolution climate projections enhance regional climate change impact studies. Eos Trans. Am. Geophys. Union, 88, 504-504.

McKinney, W., 2010: Data structures for statistical computing in Python. Proceedings of the 9th Python in Science Conference, 445, 51-56.

-—, 2012: Python for data analysis: Data wrangling with Pandas, NumPy, and IPython. O'Reilly Media, Inc.,.

NOAA National Centers for Environmental Information, 2014: State of the Climate: National Overview for August 2014. Available at http://www.ncdc.noaa.gov/sotc/national/201408 (Accessed April 11, 2016).

Norman, S. P., J. M. Varner, L. Arguello, S. Underwood, B. Graham, G. Jennings, Y. Valachovic, and C. Lee, 2009: Fire and fuels management in coast redwood forests.

O’Brien, T., L. Sloan, P. Chuang, I. Faloona, and J. Johnstone, 2013: Multidecadal simulation of coastal fog with a regional climate model. Clim. Dyn., 40, 28012812, doi:10.1007/s00382-012-1486-x.

Palmer, A. H., 1917: Fog along the California coast. Mon. Weather Rev., 45, 496-499.

Schwartz, R. E., A. Gershunov, S. F. Iacobellis, and D. R. Cayan, 2014: North American West Coast Summer Low Cloudiness: Broad Scale Variability Associated with Sea Surface Temperature. Geophys. Res. Lett., 2014GL059825, doi:10.1002/2014GL059825.

Taylor, J., R., 1997: An Introduction to Error Analysis The Study of Uncertainties in Physical Measurments. Second. University Science Books, Sausalito, CA,.

Taylor, K. E., R. J. Stouffer, and G. A. Meehl, 2011: An Overview of CMIP5 and the Experiment Design. Bull. Am. Meteorol. Soc., 93, 485-498, doi:10.1175/BAMS-D-11-00094.1.

Torregrosa, A., C. Combs, and J. Peters, 2016: GOES-derived fog and low cloud indices for coastal north and central California ecological analyses. Earth Space Sci., 2015EA000119, doi:10.1002/2015EA000119.

Walt, S. van der, S. C. Colbert, and G. Varoquaux, 2011: The NumPy Array: A Structure for Efficient Numerical Computation. Comput. Sci. Eng., 13, 22-30, doi:http://dx.doi.org/10.1109/MCSE.2011.37.

Wood, R., 2012: Stratocumulus Clouds. Mon. Weather Rev., 140, 2373-2423. 


\section{Appendix A: Additional Figures}

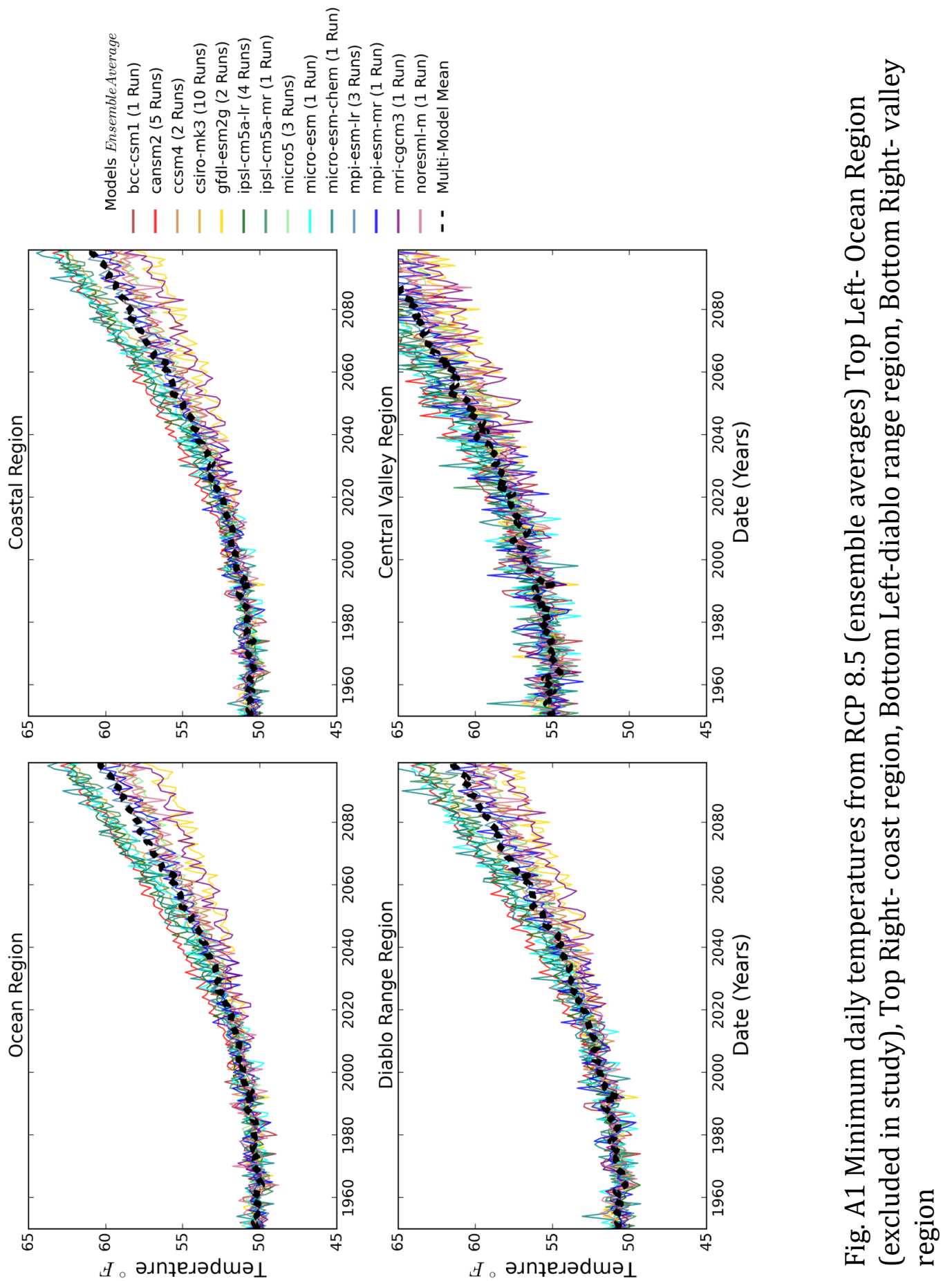




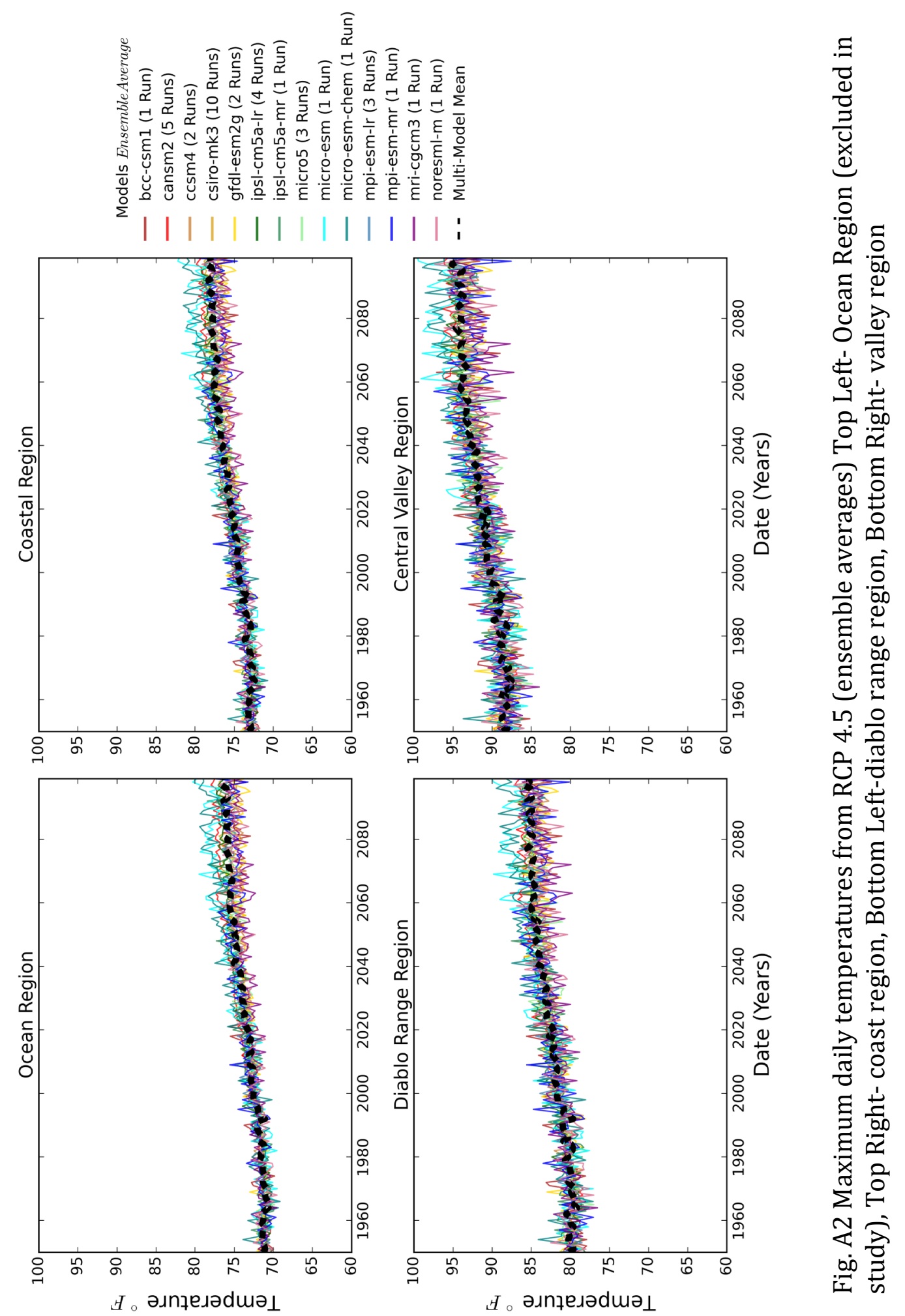




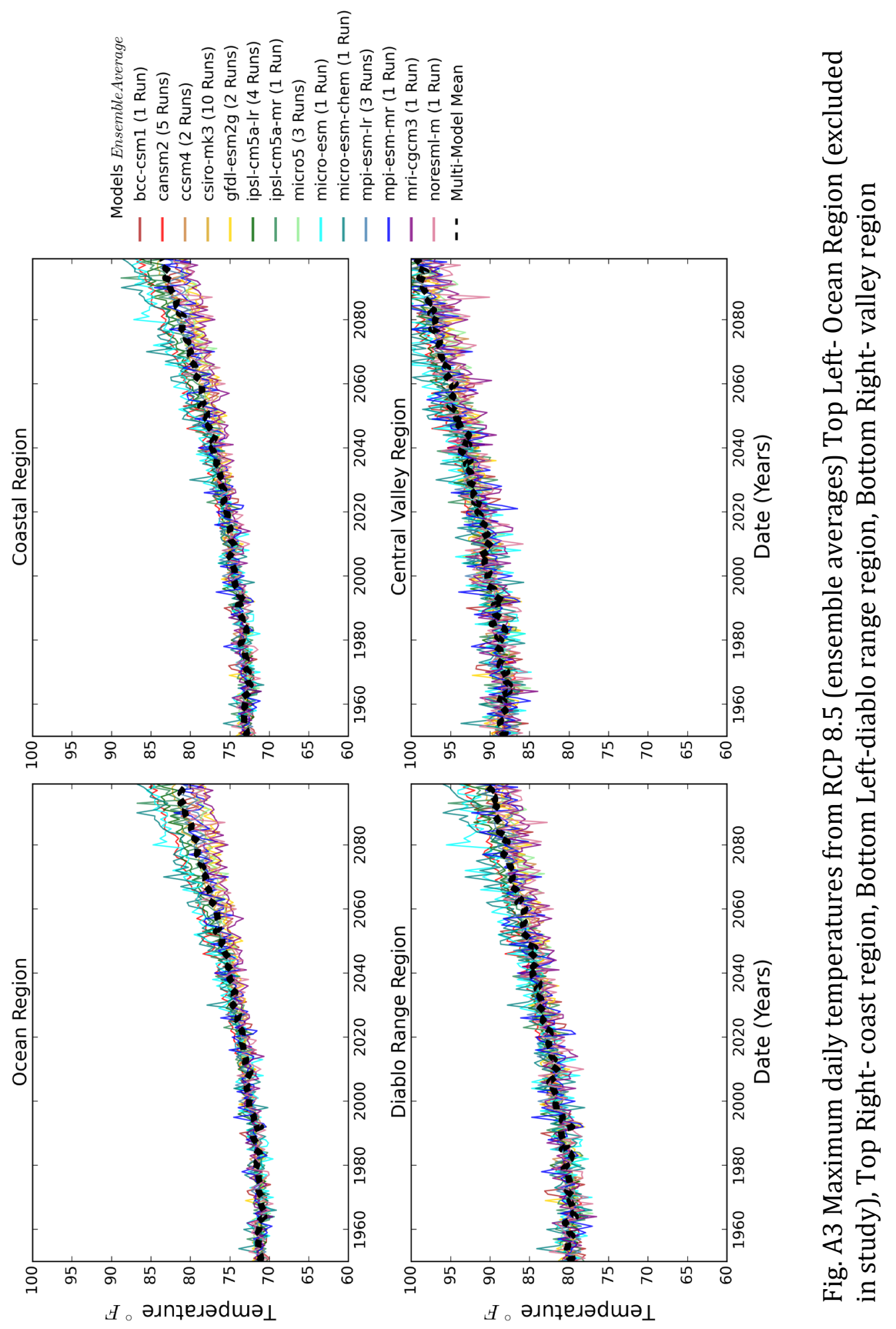




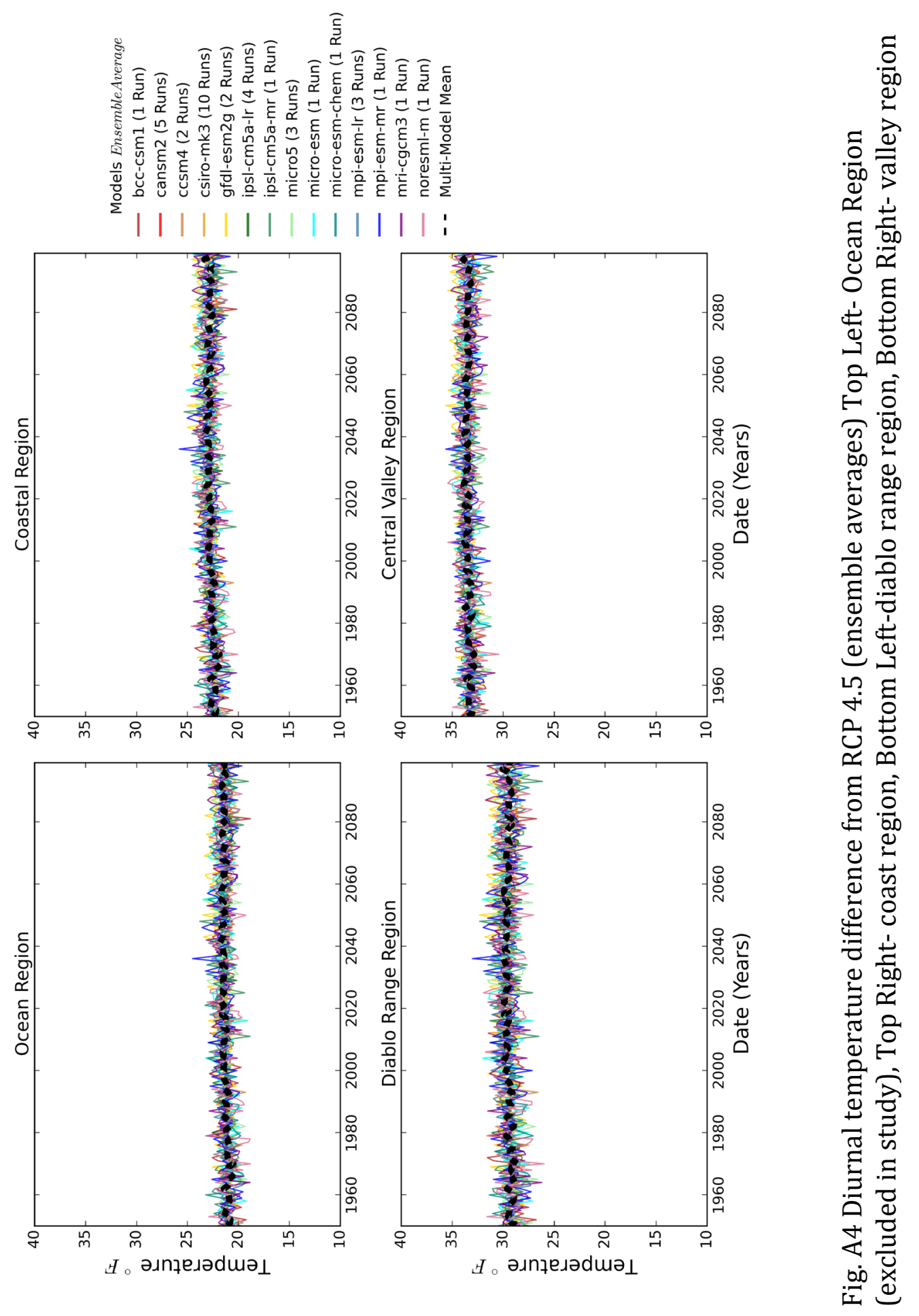




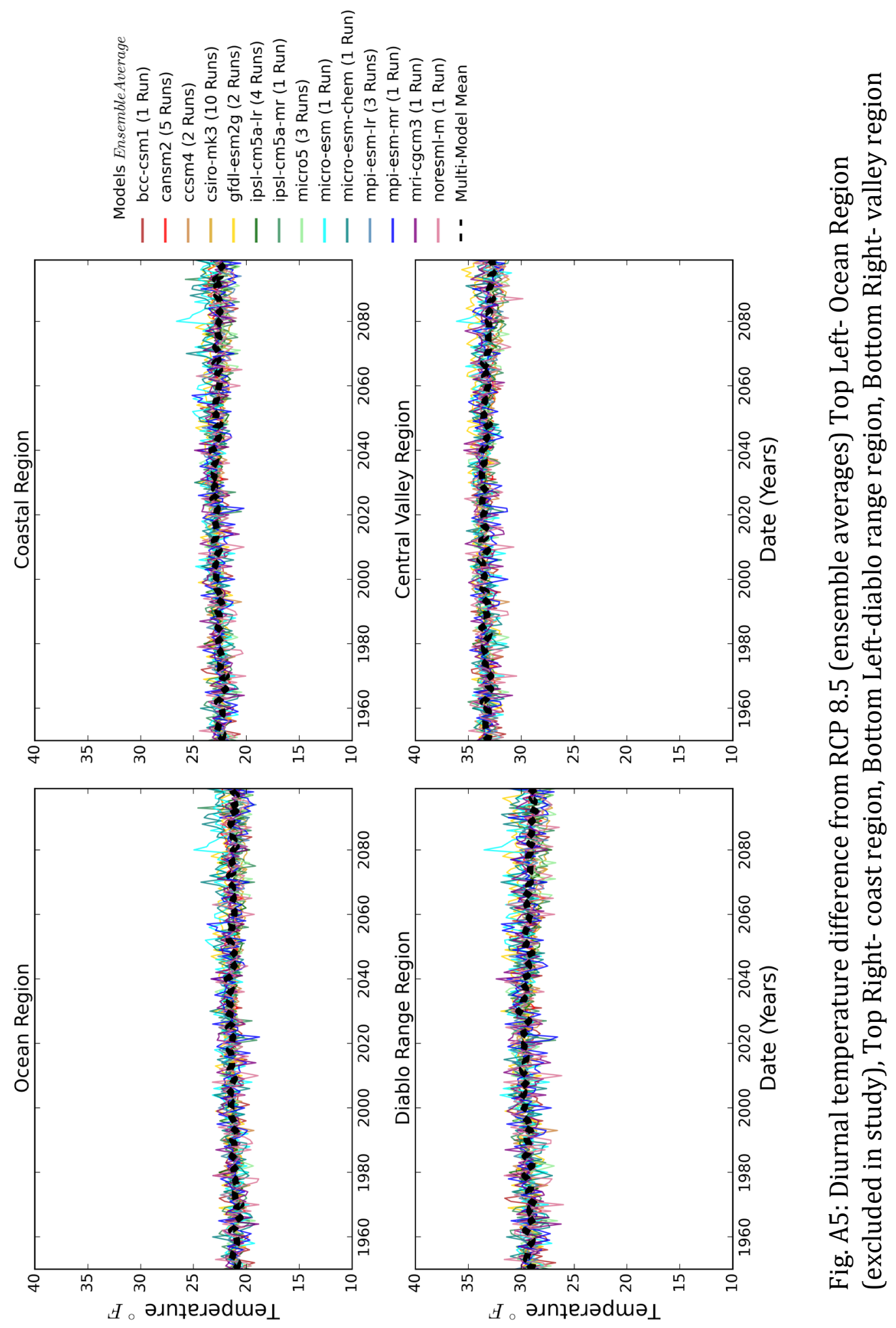

